\title{
Uma matemática na ponta dos dedos com dispositivos touchscreen
}

\begin{abstract}
Marcelo Almeida Bairral
Alexandre Rodrigues de Assis

Bárbara C. C. da Silva

\section{Resumo}

Os recursos informáticos continuam crescendo e trazendo desafios a educação. O contínuo desenvolvimento das tecnologias digitais móveis propicia inovações nas práticas pedagógicas e promove reflexões sobre os impactos causados pelas mudanças. Esse artigo é parte de uma investigação interessada no uso de dispositivos com manipulação touchscreen direcionados para os processos de ensino e aprendizagem de matemática, particularmente em geometria. Apresentaremos um levantamento de dispositivos touchscreen e os primeiros resultados de atividades desenvolvidas em dois softwares o Geometric Constructer (GC) e o Sketchometry, realizados no período de novembro de 2012 a outubro de 2013, focado na descrição e natureza desses dispositivos. Verificamos que os aplicativos (APPs) são de dois tipos: softwares e jogos. Escolhemos trabalhar com softwares, pois estes proporcionam ambientes com recursos livres para construções geométricas. Esse estudo serve de ponto de partida que pode auxiliar professores e pesquisadores interessados na inserção de dispositivos touchscreen em novas práticas educativas.
\end{abstract}

Palavras-chave: Educação Matemática, Touchscreen, Softwares.

\begin{abstract}
A mathematics at the fingertips with touchscreen devices

Computing resources continue to grow and bringing challenges to education. The continuous development of digital mobile technologies provides innovations in pedagogical practices and promotes reflection on the impacts of changes. This article is part of a research interest in the use of devices with touchscreen manipulation directed to the processes of teaching and learning mathematics, particularly in geometry. We will present a survey of touchscreen devices and the first results of activities development in the two software: Geometric Constructer (GC) and Sketchometry, conducted from November 2012 to October 2013, focused on the description and nature of these devices. We found that the applications (APPs) are of two types: software and games. We chose to work with software because they provide environments with free resources for geometric constructions. This study serves as a starting point that can help teachers and researchers interested in the inclusion of touchscreen devices in new educational practices.
\end{abstract}

Keywords: Mathematics Education, touchscreen, software.

DOI: Em andamento. 


\section{Introdução}

O presente trabalho tem como objetivos apresentar um levantamento de aplicativos direcionados a Educação Matemática para dispositivos móveis ubíquos que possuem tecnologia touchscreen e ilustrar alguns resultados iniciais de atividades implementadas nos softwares Geometric Constructer (GC) e no Sketchometry, programas que estavam disponíveis para uso gratuito na ocasião do levantamento realizado. $O$ artigo é fruto de um projeto interessado no uso de ambientes touchscreen na aprendizagem matemática. A pesquisa está orientada pela seguinte questão: Que contribuições (curriculares, cognitivas ou epistemológicas) os dispositivos touchscreen podem trazer ao aprendizado matemático?

No âmbito curricular, por exemplo, os resultados aqui ilustrados contribuem com uma apresentação e catalogação dos tipos de interfaces disponíveis atualmente. Em nossa pesquisa foram capturados 16 aplicativos, todos disponíveis na Internet. Apresentamos uma breve descrição de cada um. Os recursos foram mapeados e classificados como jogos e softwares. Os aplicativos que possuem características de jogos geralmente abordam temas da aritmética. Os softwares proporcionam ambientes de atividades livres e em sua maioria estão no contexto da geometria dinâmica.

Visando estudar na prática como se dá os processos de aprendizagem através dos dispositivos touchscreen, foi realizado um trabalho de campo com os softwares GC e Sketchometry com graduandos em matemática da Universidade Federal Rural do Rio de Janeiro (UFRRJ). Ilustraremos atividades e uma síntese do processo analítico focado na performance dos softwares.

\section{Uma breve reflexão sobre o uso de dispositivos touchscreen no ensino da matemática}

A tecnologia digital vem ganhando cada vez mais espaço na vida dos jovens. São celulares com touchscreen, notebooks, tabletes e iPads que passam a fazer parte do cotidiano da maioria dos alunos. Os equipamentos tecnológicos parecem assumir um posicionamento de destaque no ambiente escolar por parte dos discentes. 0 momento atual pode promover reflexões acerca da utilização dos aparatos de modo que possa enriquecer intervenções pedagógicas nos processos de ensino e aprendizagem (SANTOS, 2012).

Sendo assim, uma maneira de colocar literalmente a Matemática na ponta dos dedos é a utilização dos aplicativos em tabletes e iPads. A tecnologia touchscreen possibilita um contato e uma apropriação diferenciada por parte dos usuários. São novas configurações e espacialidades com os movimentos - os toques - na tela. Cabe, portanto, destacar que realizar uma manipulação 
touchscreen não e o mesmo que clicar em um mouse (DOYUN, 2011; TANG, 2010). Bairral (2013), por exemplo, ilustra essa singularidade fazendo uma analogia com os movimentos de dois tipos de artistas: o escultor e o modelador. O primeiro "talha", ponto a ponto, a obra a ser composta. 0 segundo, manipula e modela uma superfície. Esse movimento de modelar é o que associamos com a trajetória (a manipulação touch), pois ele envolve uma espacialidade diferente, não um ponto ou uma sequência de pontos. Esse artigo está elaborado nesse princípio.

A utilização dos tabletes, por exemplo, pode fornecer condições para que o aluno seja agente da construção do seu próprio conhecimento e não seja um receptor passivo de conteúdos transferidos. Além do mais, os dispositivos móveis estão mostrando-se efetivos no incremento da interação dos usuários (BASHERI et al., 2013). A configuração de interfaces touch também beneficia alunos portadores de deficiências visuais com softwares que produzem vibrações no tablete e possibilitando uma percepção do que está sendo realizado. Por exemplo, na seção dos resultados descreveremos um dispositivo visual e tátil chamado Phantom Omni. Ele tem a especificidade de permitir ao usuário manipular e sentir objetos em três dimensões.

Ressaltamos que o professor, como mediador do conhecimento e organizador de práticas educativas inovadoras, deve proporcionar aos seus alunos formas de aprender com recursos variados e que contribuam para a sua formação. E, com o uso de interfaces touchscreen não poderá ser diferente. Sendo assim, visando contribuir com a elaboração e a implementação de aulas de matemática com dispositivos móveis, ilustramos os ambientes capturados até o presente momento de nossa pesquisa.

\section{Seleção e análise de aplicativos e softwares direcionados ao ensino da matemática}

A coleta de dados ocorreu no período de novembro de 2012 a novembro de 2013. Os procedimentos para organização dos dispositivos foram:

1. Revisita aos dispositivos capturados e à revisão bibliográfica feita por Bairral (2012).

2. Revisão bibliográfica em Anais de Congressos e periódicos científicos, com prioridade aos disponíveis na Internet.

3. Busca na Internet mediante as seguintes palavras-chave: touch, touchscreen, multitouch, dispositivo móvel e App para tablets.

4. Catalogação e descrição do material levantado.

É importante ressaltar na captura dos aplicativos priorizamos aqueles que estavam essencialmente baseados na manipulação touch, isto é, dispositivos que utilizam os movimentos dos dedos na tela do tablet e não apenas toques como se fossem cliquesí.

DOI: Em andamento. 
A seguir apresentamos uma breve descrição dos dispositivos selecionados.

\subsection{Geometer Sketchpad Explorer}

O Geometer Sketchpad Explorer é um software destinado ao ensino de matemática. Ele foi desenvolvido por N. Jackiw, cientista da Key Curriculum Press Technologies (KCP). O aplicativo possui compatibilidade com iPad. É baseado no programa Geometer Sketchpad, que é muito utilizado em computadores e quadros interativos nas escolas americanas.

Com essa ferramenta o usuário será capaz de manipular e animar representações gráficas matemáticas. Ele auxilia no entendimento de conceitos da matemática elementar, geometria, álgebra, trigonometria, cálculo. Ou seja, abrange diversos ramos da matemática. Com uma interface multi-touch, simples e de fácil manuseio, o dispositivo proporciona aos alunos da Educação Infantil até os da Graduação ambientes que apoiam e auxiliam a compreensão conceitual e aprofundada da matemática.

Veja a seguir ilustrações da interface inicial do Sketchpad Explorer e uma exemplificação de situação de atividade.

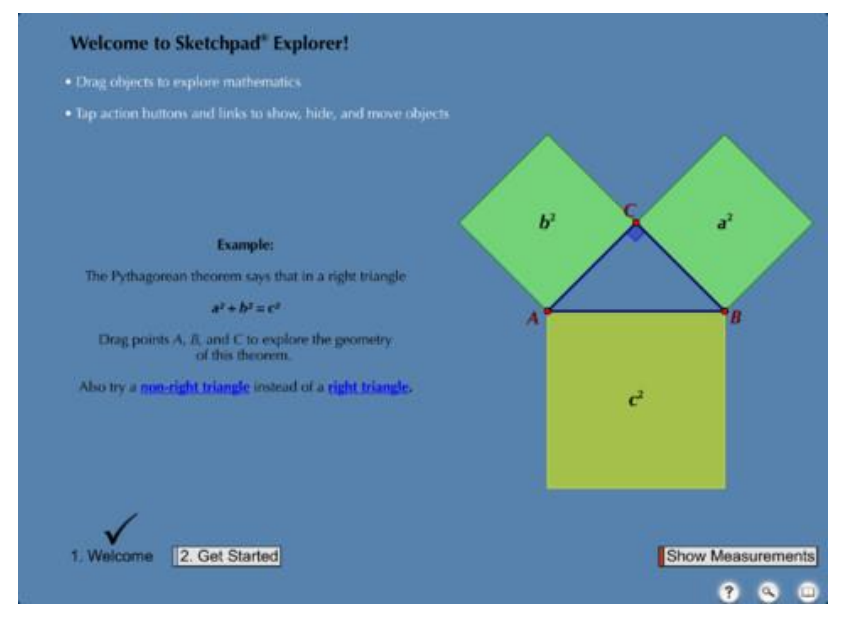

Figura 1 - Interface inicial do Sketchpad Explorer

(Fonte: ITUNES. Geometer's Sketchpad (2012)) 


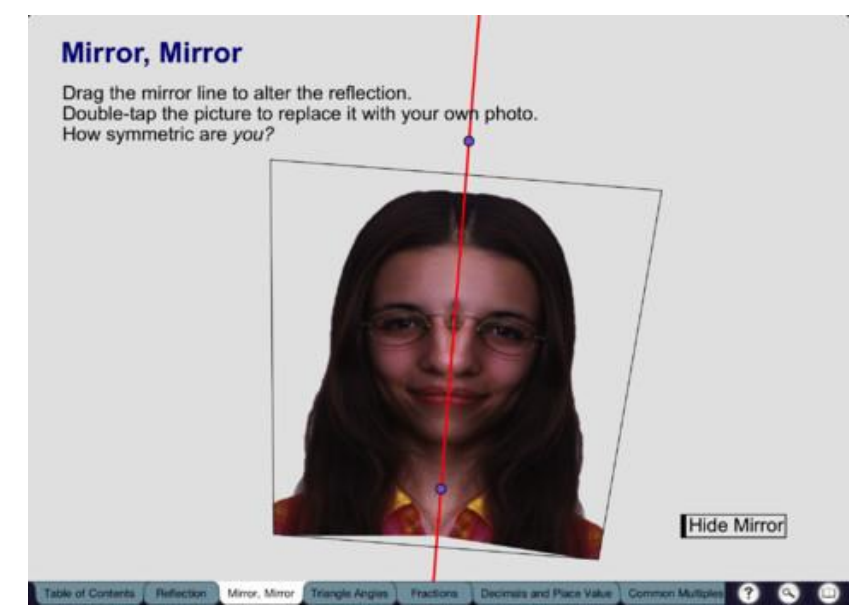

Figura 2 - Atividade que envolve os conceitos de simetria e reflexão

(Fonte: ITUNES. Geometer's Sketchpad (2012))

O Sketchpad Explorer é capaz de abrir qualquer documento do Geometer Sketchpad versão 5 e a maioria dos documentos da versão 4 . Além, de oferecer um suporte que contém dicas, sugestões de atividades para o professor aplicar em sala de aula, o programa oferece visualizações interativas que cobrem uma gama de conteúdos matemáticos. Proporciona também uma interação entre os usuários, pois apresenta um espaço onde os mesmos podem compartilhar seus esboços e criações.

\subsection{Geometric Constructer}

Geometric Constructer (GC) é um software online de geometria dinâmica livre, desenvolvido no Japão na Aichi University of Education. Para usar este programa é necessário que o internauta tenha instalado no seu computador pelo menos um dos navegadores a seguir: Internet Explorer 9 , Firefox, Safari, Opera ou Chrome o GC também é compatível com o iPad, tablete e o iPhone. Este último, por sua vez, não é o mais adequado.

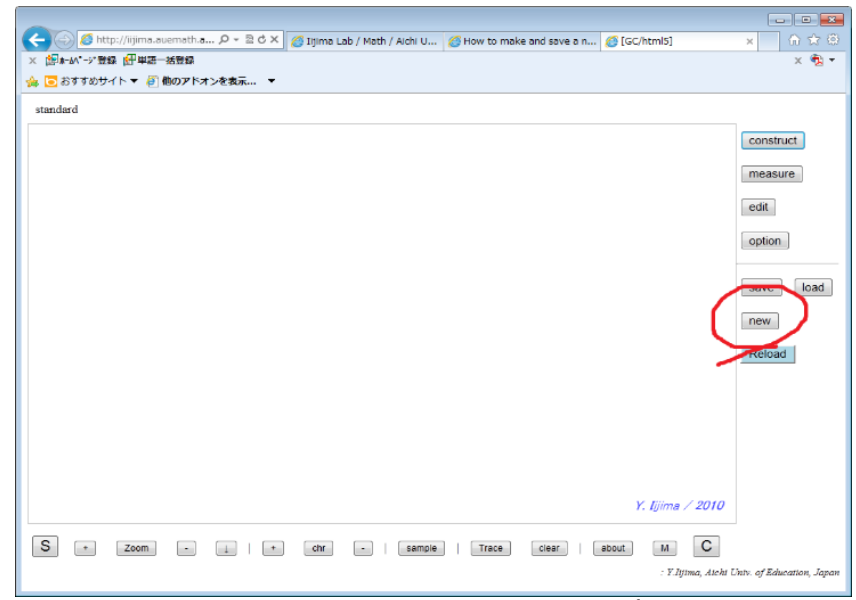

Figura 3 - Interface inicial do GC/htm/5

(Fonte: lijima, 2012)

DOI: Em andamento. 
O GC permite que seu usuário construa diversos objetos da geometria plana. Oferecendo ferramentas para a edição dessas construções, ou seja, pode-se atribuir diferentes cores para os traçados e para o preenchimento de área das figuras criadas, darem nomes entre outras opções.

O software possui um recurso que possibilita medir ângulos, segmentos e áreas dos desenhos geométricos produzidos. Mesmo sendo um programa que exige uma conexão com a internet é possível que o usuário salve suas criações tanto no servidor quanto em seu próprio computador. É possível visualizar no site desenhos de construções geométricas já prontas e que servem como exemplos e inspiração para alguma atividade educativa. Portanto, consideramos que GC enriquece a prática pedagógica, particularmente, por permitir a elaboração de atividades por parte do professor.

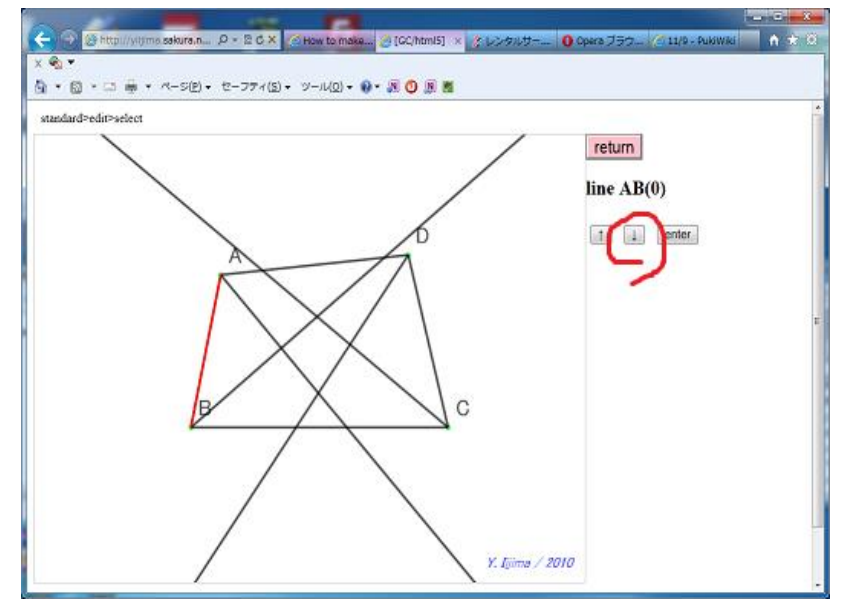

Figura 4 - Atividade do GC/htm/5

(Fonte: lijima, 2012)

\subsection{MathTappers}

Os MathTappers são aplicativos desenvolvidos exclusivamente para iPad, iPod touch e iPhones, destinados ao público infantil, têm por objetivo auxiliar no ensino da Matemática através de jogos lúdicos. Os softwares foram criados na Universidade de Victória (Canadá) pelos pesquisadores Dr. Tim Pelton e Dr. Leslee Francis Pelton. Esses aplicativos são facilmente encontrados no web site da App Store.

Existem seis tipos de MathTappers disponíveis no mercado hoje. Cada aplicativo é um jogo que ajuda os alunos a aprenderem os conceitos matemáticos um de cada vez. A ideia é formar uma coleção de jogos educativos gratuitos para o ensino de matemática. Os MathTappers disponíveis são:

MathTapper - Numberline: É um jogo que desafia os participantes a encontrarem a localização dos números em uma reta numérica. Trabalhando com o conjunto de números reais. 


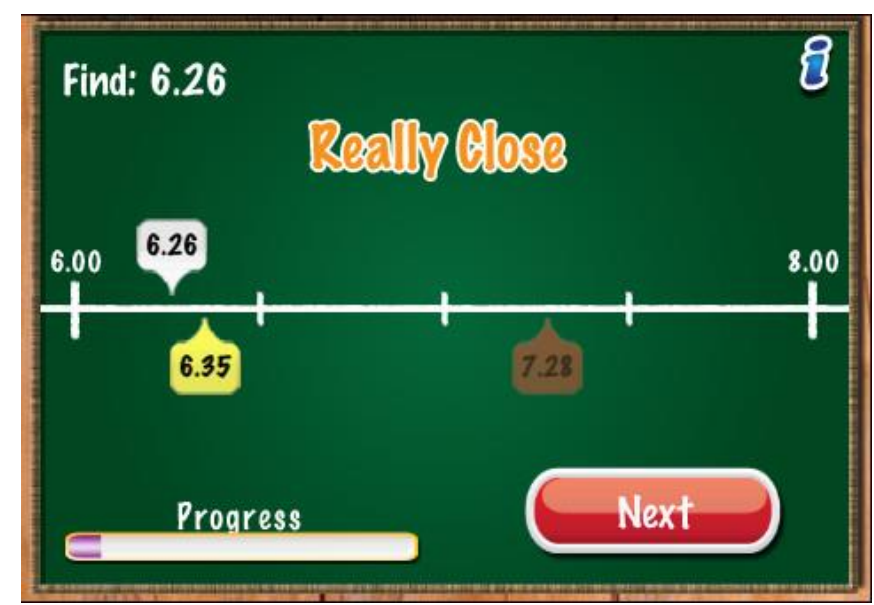

Figura 5 - Atividade relacionada ao MathTapper - Numberline

(Fonte: ITUNES, MathTapper - Numberline (2012))

MathTapper - Findsums: É um jogo feito para auxiliar o participante a entender o sentido da soma e da subtração, ajudando-o a desenvolver um raciocínio rápido em relação aos cálculos mentais de adição e subtração. $O$ aplicativo oferece também relatórios relativos ao desempenho para que os pais ou professores acompanhem a evolução e o progresso da criança.

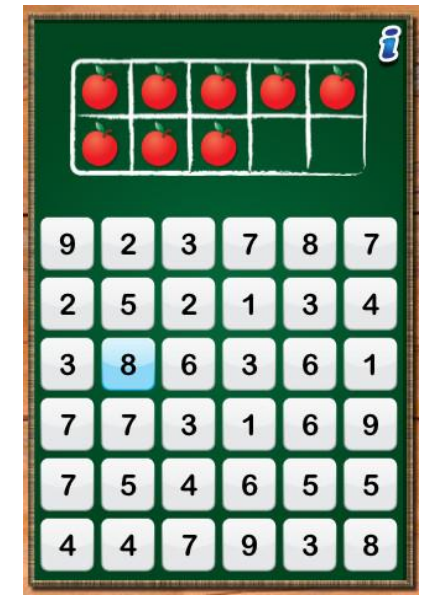

Figura 6 - Atividades relacionadas ao MathTapper - Findsums

(Fonte: ITUNES. MathTapper - Findsums (2012))

MathTapper-Multiples: É um jogo simples que auxilia o aluno a compreender o sentido de multiplicar e dividir números inteiros. Ajuda a desenvolver a habilidade de efetuar rapidamente esses cálculos, obtendo total domínio e segurança sobre o conteúdo. Este aplicativo também fornece relatórios referentes ao progresso do aluno.

DOI: Em andamento. 


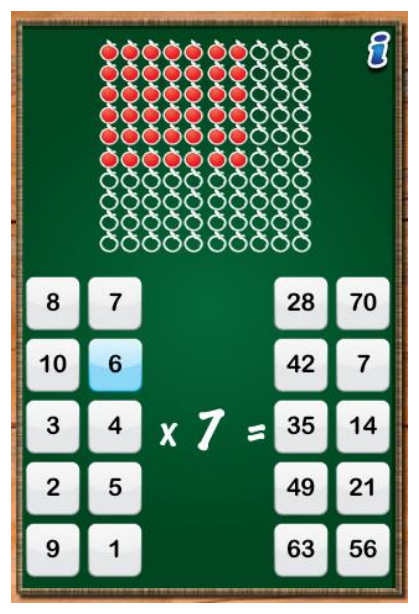

Figura 7-Atividades relacionadas ao MathTapper-Multiples

(Fonte: ITUNES. MathTapper - Multiples (2012))

MathTapper-Clockmaster: É um jogo para auxiliar o aluno a estabelecer uma conexão entre horas e minutos, ajudando-o a tornar-se fluente na leitura e no ajuste do tempo em relógios digitais e analógicos.

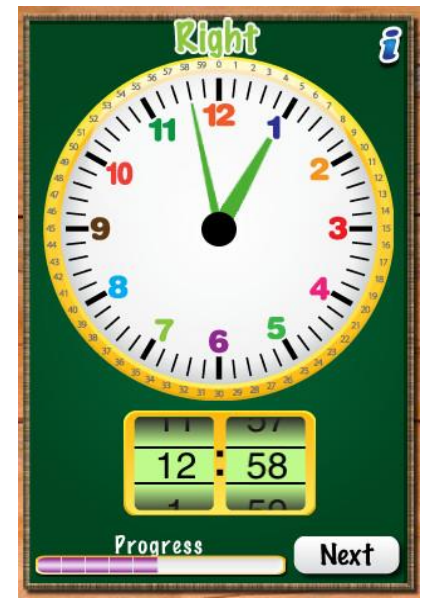

Figura 8 - Atividades relacionadas ao MathTapper - Clockmaster

(Fonte: ITUNES. Tapper-Clockmaster (2012))

MathTapper - Estimate Fractions: É um jogo projetado para auxiliar o discente a construir uma compreensão intuitiva sobre as frações, ajudando-o a relacioná-las com números mais próximos da metade de outros valores, para depois ampliar seu conhecimento, desafiando-o a utilizar estimativas de frações em problemas de adição e subtração. 


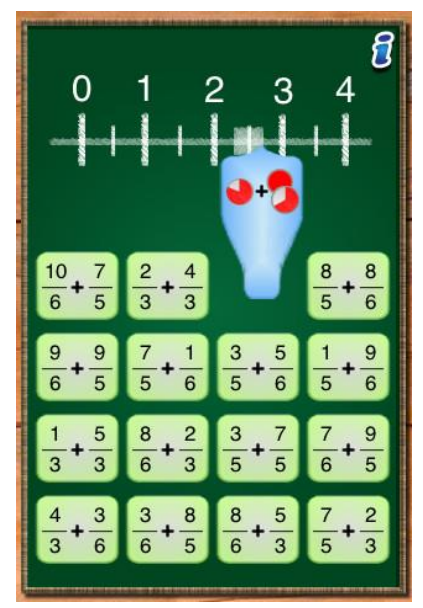

Figura 9 - Atividades relacionadas ao MathTapper - EstimateFractions

(Fonte: ITUNES. MathTapper - EstimateFractions (2012))

MathTapper - Equivalentes: Este aplicativo desafia os jogadores a formarem grupos de azulejos (pares ou trios) mostrando frações equivalentes, decimais ou porcentagens. Para ajudar o jogador, o recurso pode apresentar uma reta numérica ou um gráfico mostrando o valor da primeira fração selecionada.

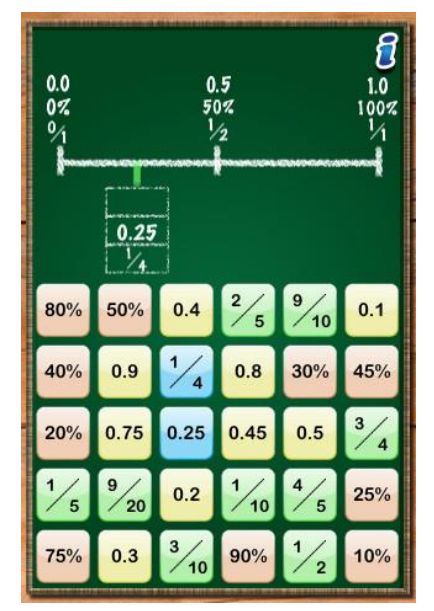

Figura 10-Atividades relacionadas ao MathTapper - Equivalentes

(Fonte: ITUNES. MathTapper - Equivalentes (2012))

Portanto, observa-se um padrão entre os aplicativos do MathTappers e abrangência nos temas. Ele começa com representações na reta real, passando para as operações (soma, subtração, multiplicação, divisão), representações gráficas, aplicações no dia a dia, medição do tempo através do relógio e conceitos de. Ressaltamos, então, que estes recursos podem trazer benefícios bastante significativos ao processo de ensino e aprendizagem. Vejamos mais.

DOI: Em andamento. 


\subsection{Haptic and Aural Exploration Software}

Aplicativo desenvolvido com o intuito de auxiliar alunos com deficiência visual no ensino de Matemática. Ele foi criado por Jenna Gorlewicz, uma estudante de pós-graduação no Laboratório de Design Médico e Eletromecânica (MED Lab.) da Universidade de Vanderbilt e seu orientador Robert Webster, professor assistente de engenharia mecânica, que dirige o laboratório. A princípio o software tem compatibilidade com tabletes. Está sendo testado por dois alunos com deficiência visual que estão cursando o Ensino Médio. Abrange os conceitos da álgebra, geometria entre outros conteúdos matemáticos que sem a visão normal ficam difíceis de compreender.

Quando o dedo toca uma linha desenhada na tela o tablete vibra silenciosamente. Deslizando o dedo para frente e para trás é possível sentir a vibração do vai e vem e isso permite aos alunos traçarem o caminho da linha. Segundo Salisbury (2012), em depoimento, os discentes dizem que de início o mais difícil é formular mentalmente a figura que está construindo, mas em pouco tempo eles se familiarizam com o aplicativo e logo afirmam que aprender matemática com este recurso se torna muito mais fácil.

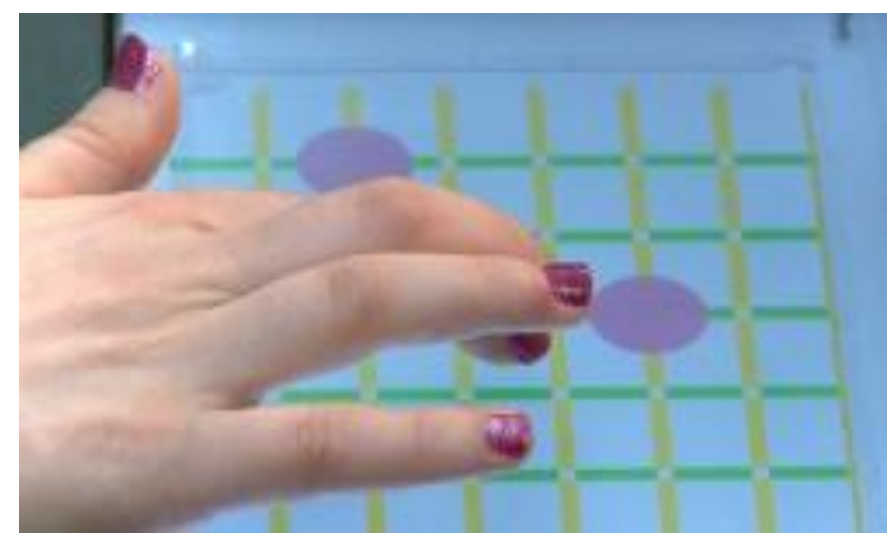

Figura11 - Testando o aplicativo - Mão deslizando em uma grade na tela do tablete que vibra quando o dedo toca uma linha

(Fonte: SALISBURY, David (2012))

\subsection{Fingu}

O aplicativo Fingu é um jogo desenvolvido para iPad destinado a crianças entre 4 e 8 anos de idade. $O$ jogo tem por objetivo estimular o reconhecimento rápido dos algarismos de 1 a 10, auxiliando assim na aprendizagem da contagem. O Fingu foi criado por pesquisadores da Universidade de Gotemburgo e da Universidade Kristianstad, na Suécia.

Exibindo uma determinada quantidade de objetos em movimento por um curto período de tempo o jogador deve rebater colocando o mesmo número de dedos (em qualquer lugar) na tela antes que o tempo se esgote. Ao colocar os dedos na tela as impressões digitais da criança ficam 
vermelhas e quando a resposta é registrada as mesmas ficam verdes. O jogador é informado se a resposta está correta ou não. De acordo com a quantidade de acertos a criança vai avançando nos níveis do jogo.

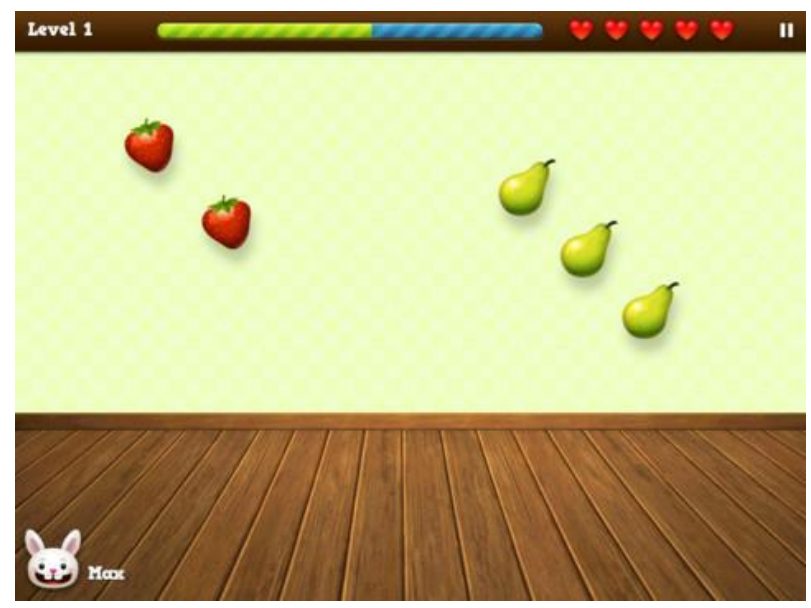

Figura 12 - Atividade do jogo Fingu

(Fonte: ITUNES. Fingu (2012))

\subsection{Numeration}

O Numeration (numeração) é um jogo destinado a crianças do primeiro segmento do Ensino Fundamental. Foi desenvolvido pelo professor UlliKortenkamp (didática das matemáticas na Universidade Martin Luther de Halle Wittenberg, Alemanha) e a professora SilkeLadel (didática do ensino no Departamento de Matemática, Universidade de Saar, Alemanha).

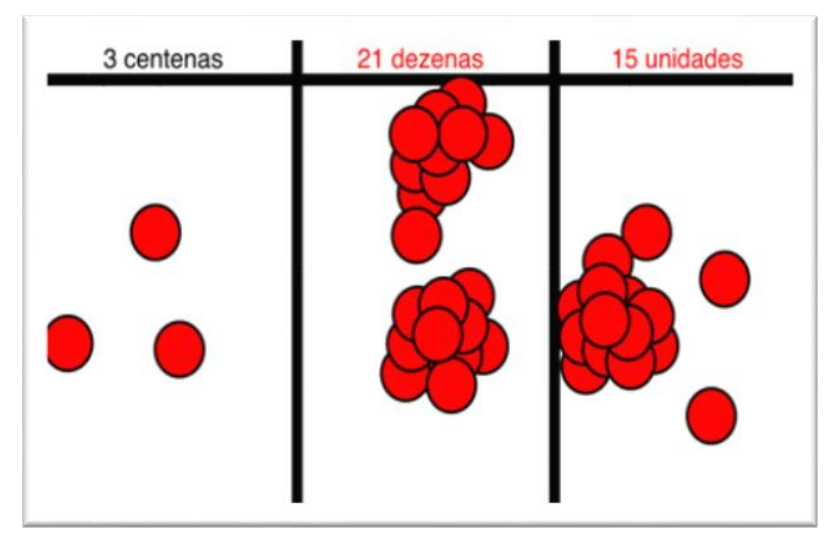

Figura 13 - Atividade do jogo Numeration

(Fonte: ITUNES. Numeration (2012))

O objetivo principal deste jogo é apoiar e promover o desenvolvimento de conceitos matemáticos para a composição e decomposição de um número no sistema decimal. Auxilia também na compreensão das operações básicas de soma e subtração. A interface do aplicativo é

DOI: Em andamento. 
como um quadro interativo no qual o usuário poderá agitar o iPad para efetuar alguma jogada, por exemplo. Possui tradução para vinte e um idiomas diferentes, inclusive, o português.

\subsection{Sketchometry}

Sketchometry é um software gratuito de geometria dinâmica. É implementado em HTML5 e roda nos principais navegadores, (Firefox, Chrome, Safari, IE $9+$, Opera). Possui versão disponível em Língua Portuguesa. As construções podem ser salvas utilizando Dropbox, SkyDrive, UbuntuOne, Google Drive e WebDav. Produzido por Alfred Wassermann da Universidade de Bayreuth, com a última atualização realizada em julho de 2013, versão 0.4.4. Roda em desktops, quadros interativos e dispositivos móveis com iOS, Android 4 +.

No Sketchometry, como um software de geometria dinâmica, as construções com os objetos livres, podem ser movimentados para a realização de conjecturas, e as modificações são atualizadas automaticamente, caso esteja utilizando o software online, visto que em desktop, há a possibilidade de baixar o programa em zip, instalar e utilizá-lo offline.

O software ainda possui limitações, pois se trata de uma versão beta, mas vem ocorrendo atualizações, como problemas no zoom, travamento, idiomas e opções de locais para importar e exportar as construções realizadas.

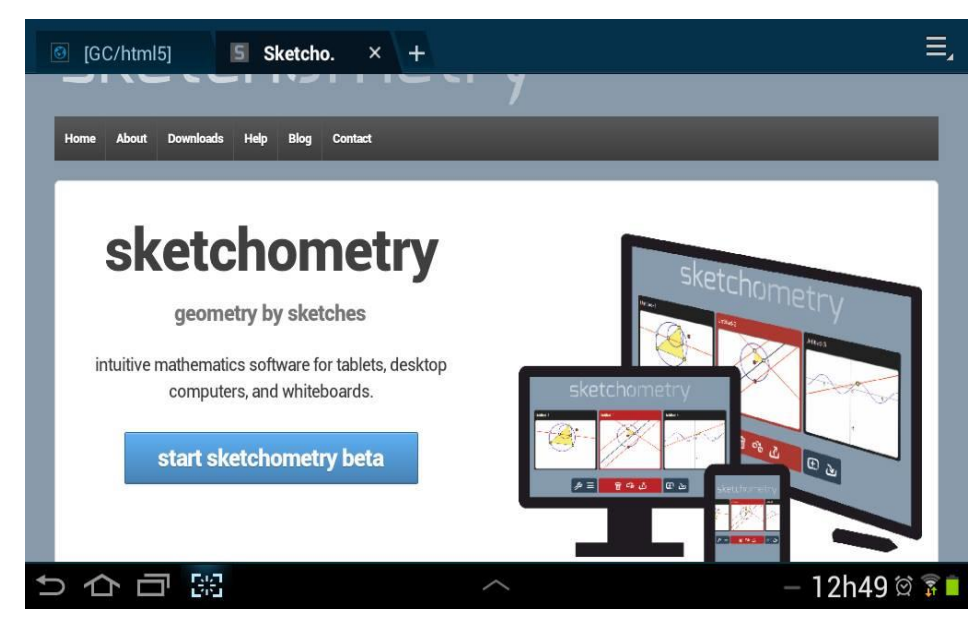

Figura 14 - Página inicial do software Sketchometry

(Fonte: Elaboração dos autores.)

Em se tratando dos dispositivos móveis, mais especificamente dos tabletes, é necessária uma conexão estável para que a resposta do programa seja realizada de forma satisfatória, assim como a importação e exportação das construções. Verifica-se que o software pode ser executado em diferentes plataformas, possui uma interface funcional e agradável, e que possibilita a utilização de forma prática dos recursos disponíveis no dispositivo. 


\subsection{Geogebra Tablets Apps}

Geogebra é um software gratuito que possui uma multi-plataforma de matemática dinâmica para todos os níveis de ensino que junta geometria, álgebra, tabelas, gráficos, estatísticas e cálculo em um ambiente fácil de usar. O programa reúne as ferramentas tradicionais de geometria com outras mais adequadas à álgebra e ao cálculo. Foi desenvolvido por Markus Hohenwarter em 2001, na Universidade Salzburg. Atualmente foi implementado o Geogebra Tablets Apps uma adaptação do software para tabletes e dispositivos móveis que possuem a tecnologia touchscreen, este por sua vez possui os mesmos recursos que o Geogebra convencional.

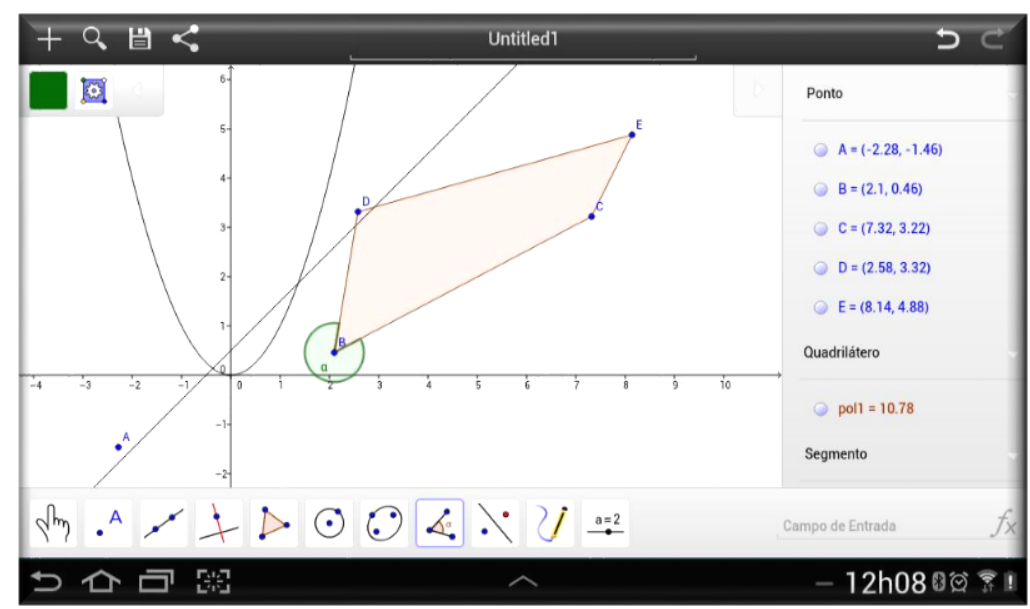

Figura 15 - Tela do Geogebra tablets apps

(Fonte: Elaboração dos autores.)

A princípio o Geogebra Tablets Apps está disponível em versão beta e pode ser utilizado online ou através do download pelo site http://www.geogebra.org/download. O aplicativo é integrado ao Geogebra tube, uma página de pesquisa sobre materiais e tutoriais do programa, sua barra de ferramenta é do tipo toolbar, isto é, apresenta uma interface gráfica, assim como o Geogebra para computadores. Também possui a barra de entrada (bar input) para adição de funções e coordenadas.

\subsection{Geometry Pad}

Geometry Pad versão 2.0.3 é um programa de geometria dinâmica desenvolvido para rodar em tabletes com sistemas iOS ou Android. Há uma versão de demonstração disponível, mas nem todas as ferramentas estão habilitadas. O programa é instalado no dispositivo do tipo tablet e é utilizado offline. O aplicativo possui ferramentas para construções de formas geométricas fundamentais e possibilita a exploração de suas propriedades, assim como verificar as medidas e as equações das formas construídas.

DOI: Em andamento. 


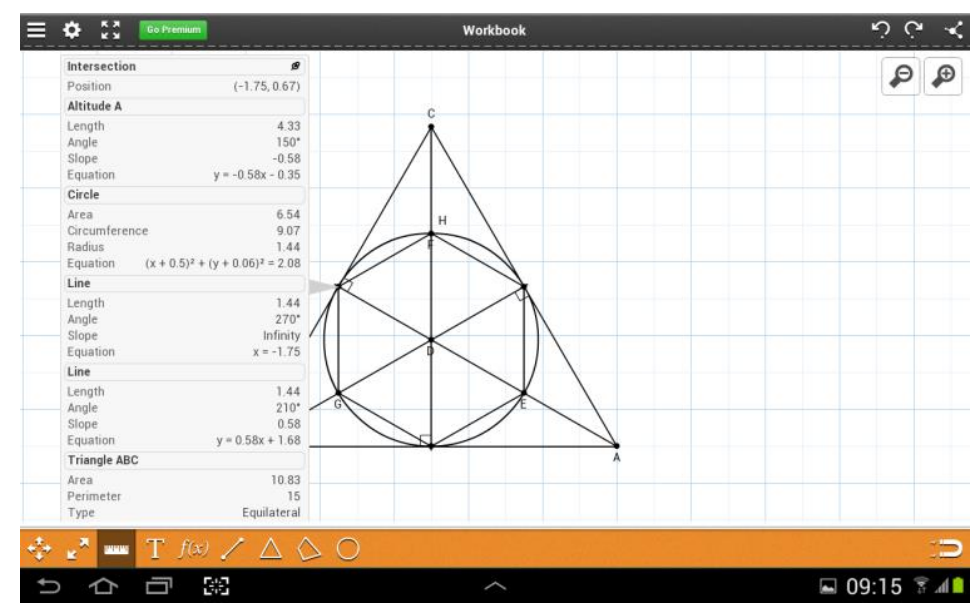

Figura 16 - Construção realizada no Geometry Pad.

(Fonte: Elaboração dos autores.)

As ferramentas para realizar as construções são disponibilizadas em uma barra na parte inferior da área de trabalho. As construções são salvas no Drobox ou no próprio dispositivo (tablet). É possível: realizar a edição de cores, destacar as linhas e os pontos demarcados, ampliar e reduzir com o deslizar dos dedos, modificar formas, medir área e o ângulo de uma figura, observar a medida de um segmento (utilizando o multitouch), personalizar construções, efetuar construções polígonos pré-definidas (quadrado, losango, triânulo isósceles e triângulo equilátero), traçar cônicas e trabalhar com as transformações (rotação, translação e reflexão).

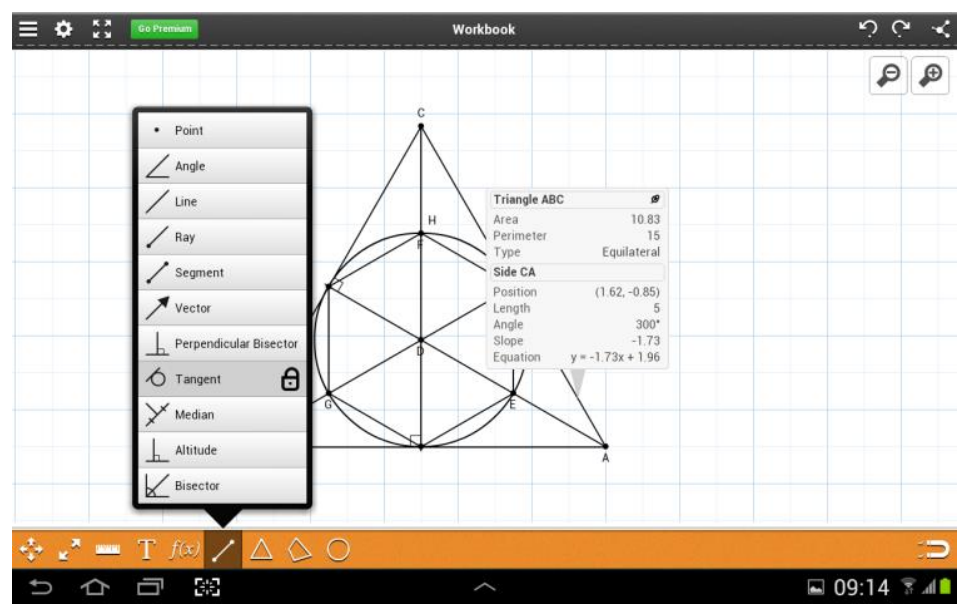

Figura 17-Visualizando as medidas após a seleção do pé da altura relativa ao lado $B C$.

(Fonte: Elaboração dos autores.)

O programa também oferece o recurso de inclusão de anotações, na área de trabalho, que podem ser editadas. Com o Geometry Pad é possível realizar atividades de investigativas, elaborar 
e explorar conjecturas, com o objetivo de validá-las ou refutá-las. A realização de anotações no Workbook (área de trabalho) é um elemento que pode favorecer o aprendizado de forma colaborativa, uma vez que o programa permite o compartilhamento das construções.

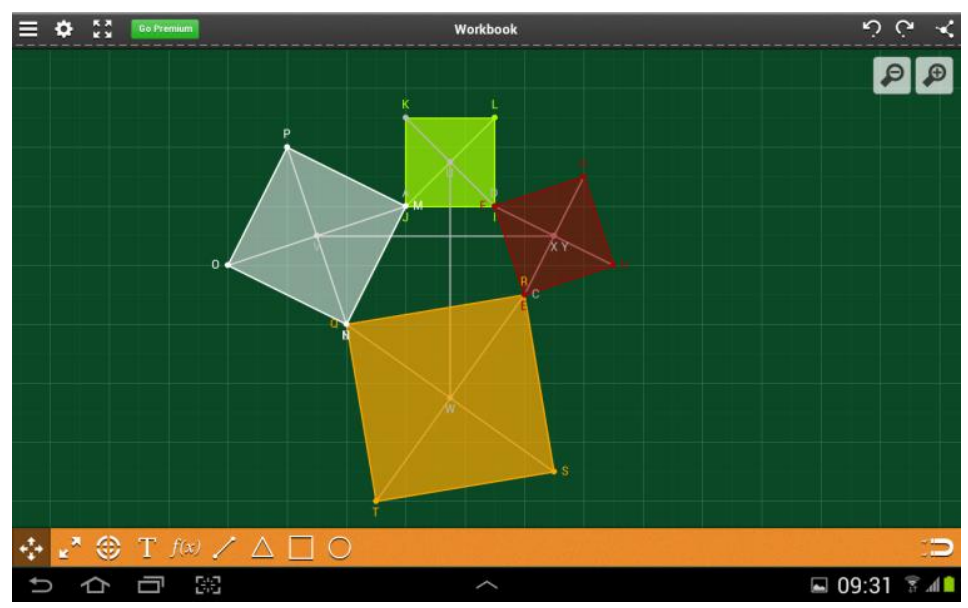

Figura 18 - Worbook resultante de uma atividade investigativa - Teorema de Aubel.

(Fonte: Elaboração dos autores.)

O programa está disponível no endereço http://www.stemonmobile.com/.

\subsection{Multibase}

O Multibase versão 1.0 é um aplicativo que tem como base o material dourado, desenvolvido a partir da pesquisa de mestrado de Rony C. O. Freitas - Doutor em Educação e líder do Grupo de Estudos e Pesquisas em Educação Matemática do Espírito Santo/GEPEM-ES - intitulada "Um Ambiente para Operações Virtuais com o Material Dourado". O material dourado é um elemento de um conjunto de materiais pedagógicos manipulativos, e foi desenvolvido pela italiana Maria Montessori, que propicia a compreensão de algoritmos operatórios.

DOI: Em andamento. 


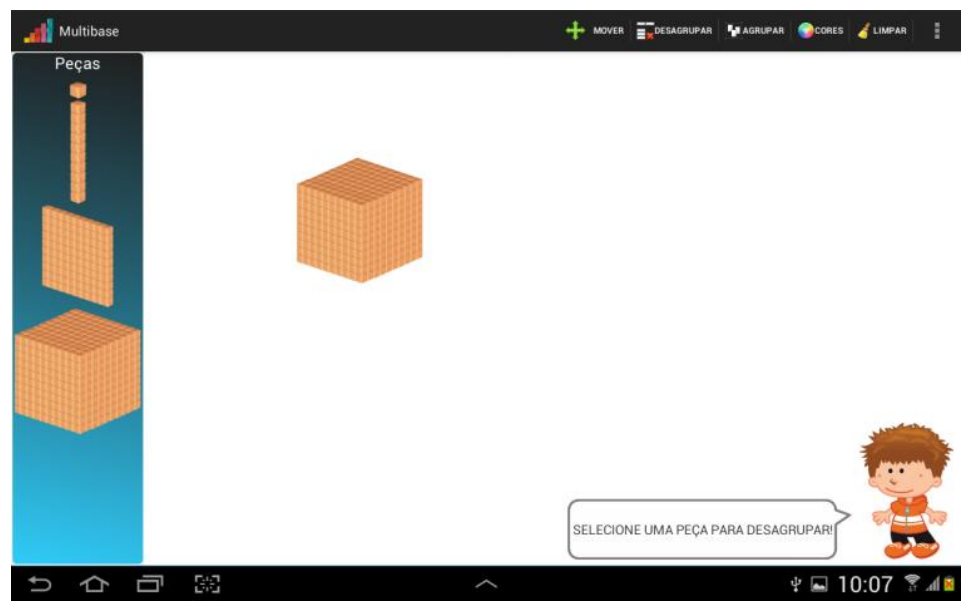

Figura 19 - Seleção da ferramenta "desagrupar".

(Fonte: Elaboração dos autores.)

É um programa gratuito, que pode ser baixado pelo Google play e utilizado offline. Com uma interface agradável, o aluno pode arrastar as formas para "área de trabalho" e realizar as atividades proposta pelo professor de forma mais lúdica. Possibilita o aprendizado de do sistema de numeração, valor posicional e o entendimento de alguns métodos utilizados nas operações matemáticas fundamentais.

O objetivo é a oferta de mais um recurso para o trabalho com material manipulativo para as séries iniciais do Ensino Fundamental. As ferramentas (mover, desagrupar, agrupar, cores e limpar) são disponibilizadas na parte superior. No canto esquerdo, são os "objetos" que podem ser escolhido e arrastado para a "área de trabalho". Quando uma das ferramentas é selecionada, aparece a imagem com a mensagem indicando a ação da ferramenta.

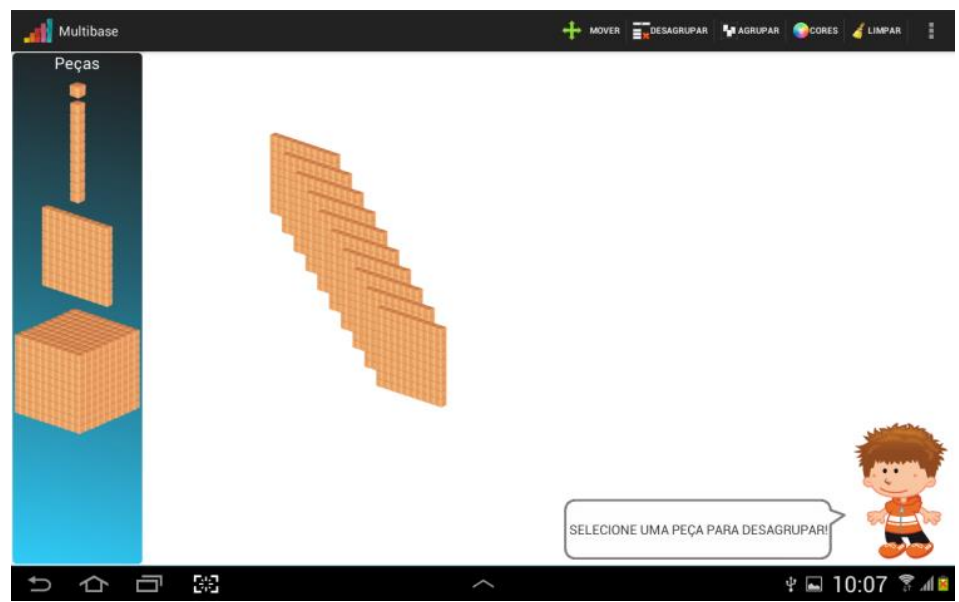

Figura 20 - Resultado da ação "desagrupar" o cubo maior.

(Fonte: Elaboração dos autores.) 


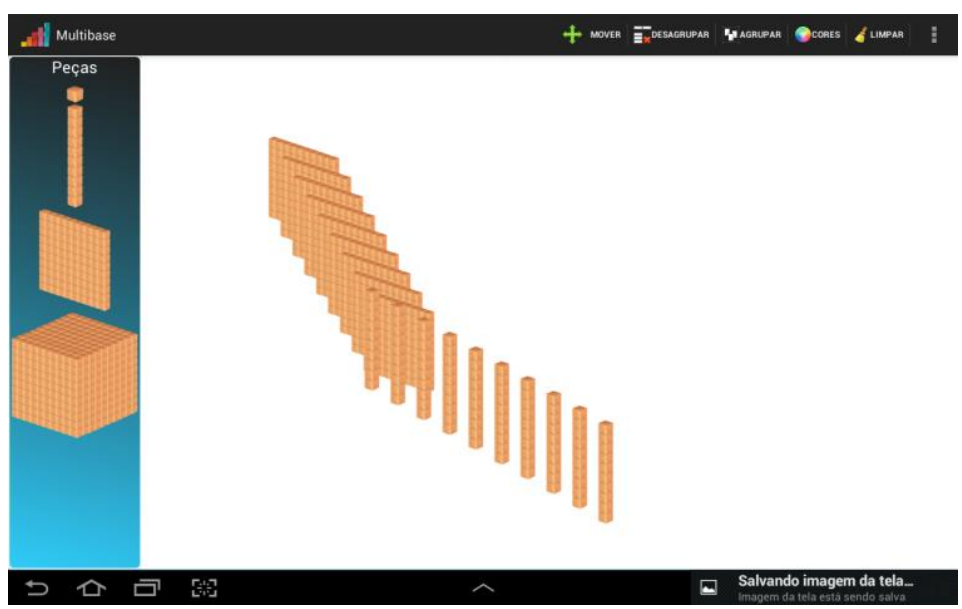

Figura 21 - Resultado da ação "desagrupar" uma placa.

(Fonte: Elaboração dos autores.)

A elaboração de atividades para a exploração do Multibase, abordando conceitos relativos às operações e a ideia de valor posicional, por exemplo, é possível com a manipulação das peças utilizando as bases 3, 5 ou 10. Após "agrupar" e "desagrupar", o aluno deve identificar o local em que a nova peça deverá ser arrastada.

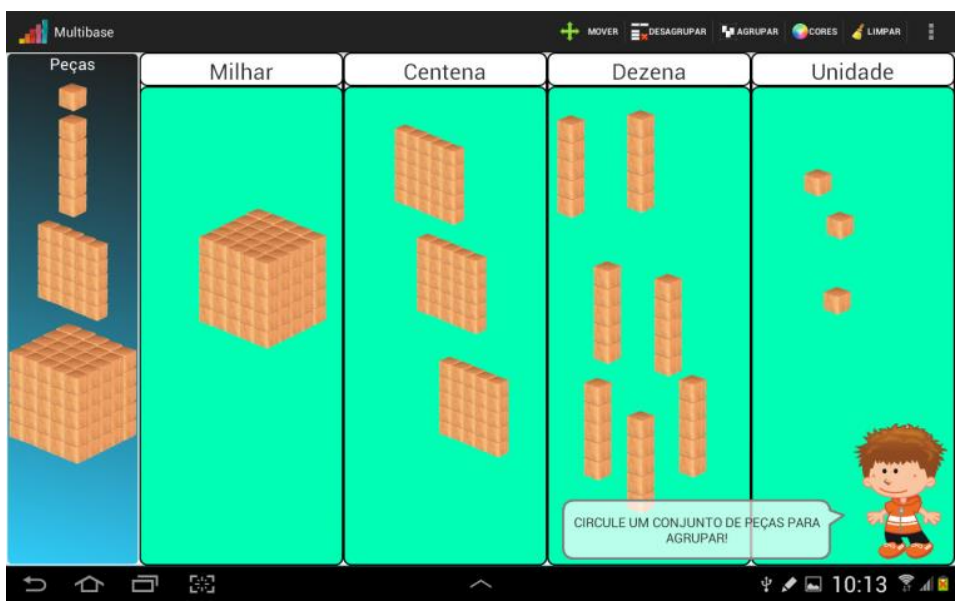

Figura 22 - Trabalhando o valor posicional e formação de grupos na base 5.

(Fonte: Elaboração dos autores.)

DOI: Em andamento. 


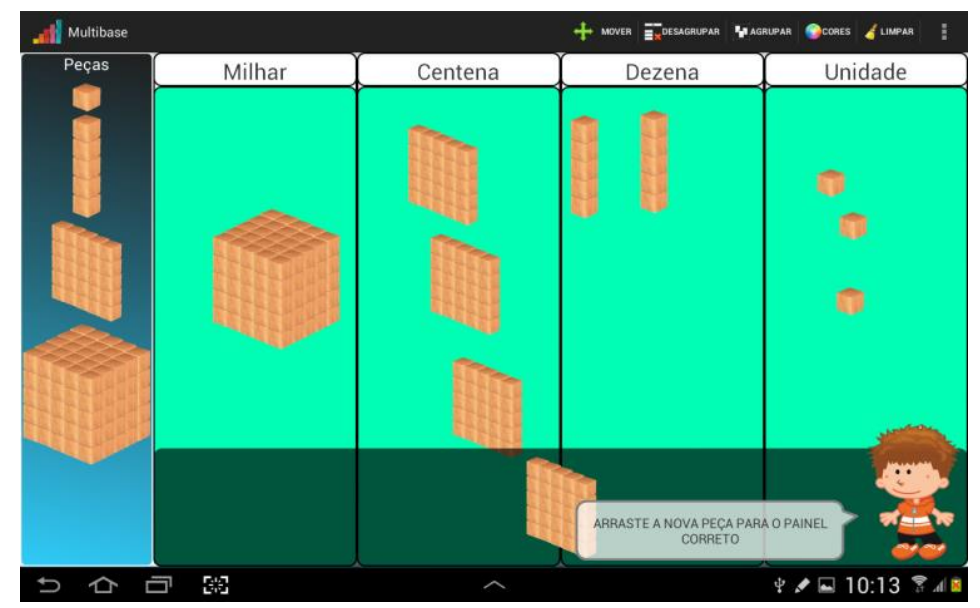

Figura 23 - Resultado da formação do grupo na base 5 .

(Fonte: Elaboração dos autores.)

O recurso facilita o entendimento da expressão "vai um" ou "emprestou um ao...", com a utilização das ferramentas "agrupar" e "desagrupar", respectivamente.

\subsection{Graphing Caculator by Mathlab}

O Graphing Caculator by Mathlab versão 2.3.66 é um programa que pode substituir algumas calculadoras gráficas. Roda em dispositivos com o sistema iOS ou Andriod. Não é um programa gratuito, mas há possibilidade de manipular algumas ferramentas em uma versão demo e observar algumas de suas potencialidades. Neste caso há necessidade de conexão com a internet para sua utilização. 


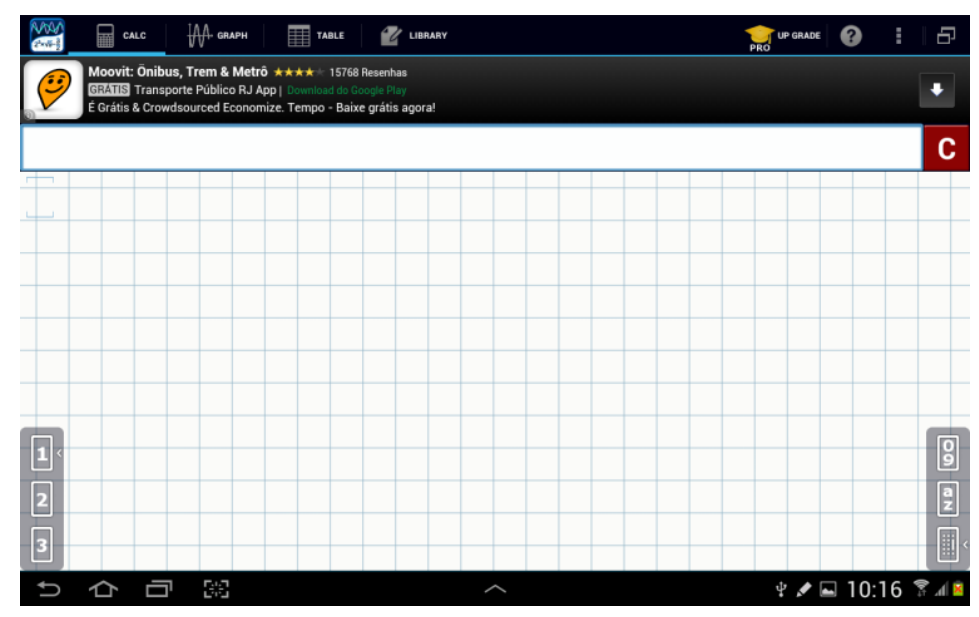

Figura 24 - Tela inicial do Graphing Caculator by Mathlab .

(Fonte: Elaboração dos autores.)

Na parte superior há a barra de seleção de ações indicando as opções: CALC (calculadora), GRAPH (construção do gráfico), TABLE (tabela podendo utilizar várias funções) e LIBRARY (biblioteca - disponível somente na versão PRO ).

O aplicativo possibilita a construção de um gráfico com múltiplas funções e durante a digitação da função, os valores vão sendo mostrados na área de construção do gráfico. As construções são salvas como imagens - versão de demonstração.

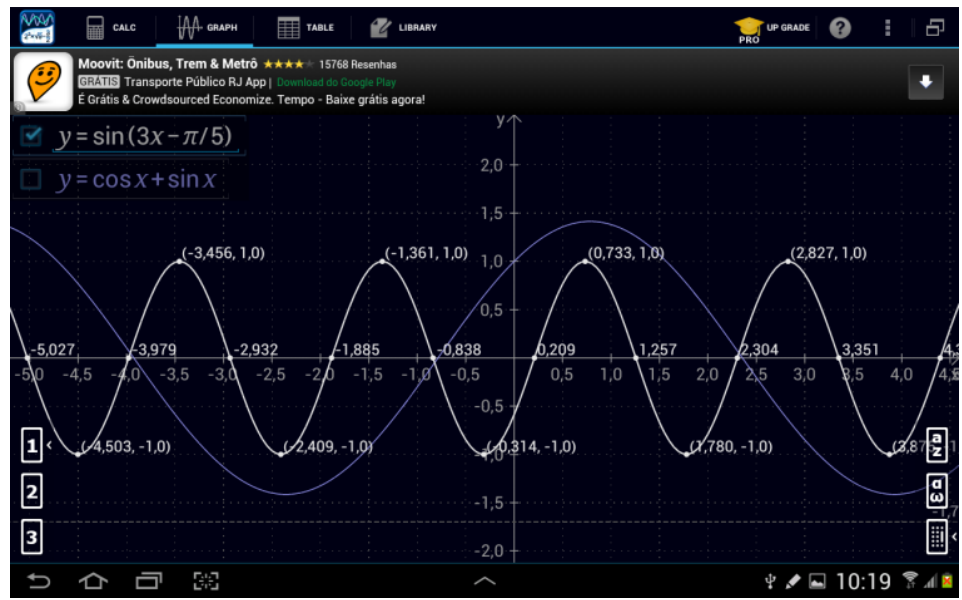

Figura 25 - Tela gerada a partir da plotagem da combinações de funções.

(Fonte: Elaboração dos autores.)

Um ponto forte do recurso que merece ser ressaltado é a questão da precisão, podendo ser observado no "zoom". E apesar de uma interface pouco atraente - muita informação na área de

DOI: Em andamento. 
trabalho - o recurso se destaca pela grande possibilidade de combinações de operações que podem ser realizadas.

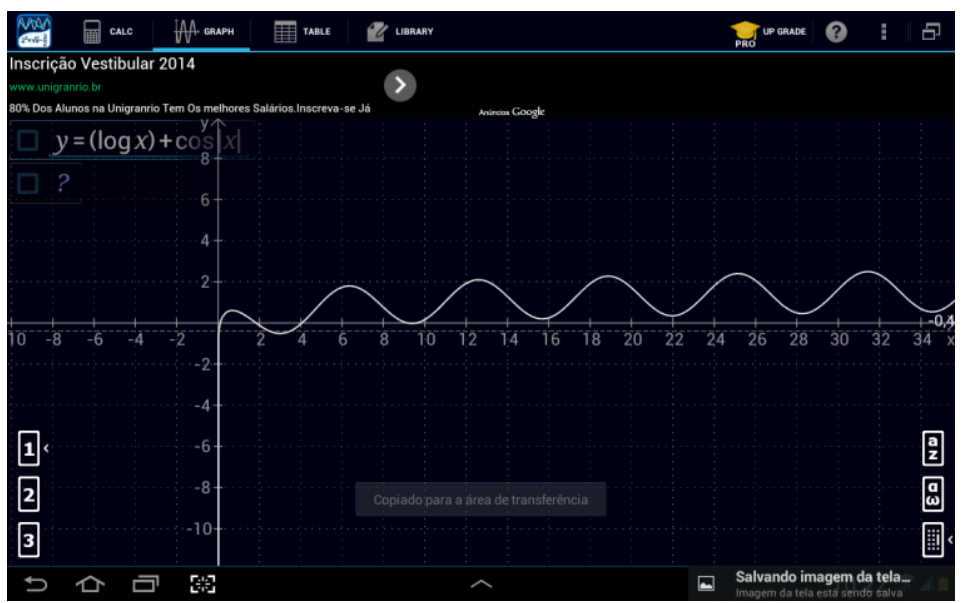

Figura $26-$ Gráfico da função $y=\log (x)+\cos |x|$.

(Fonte: Elaboração dos autores.)

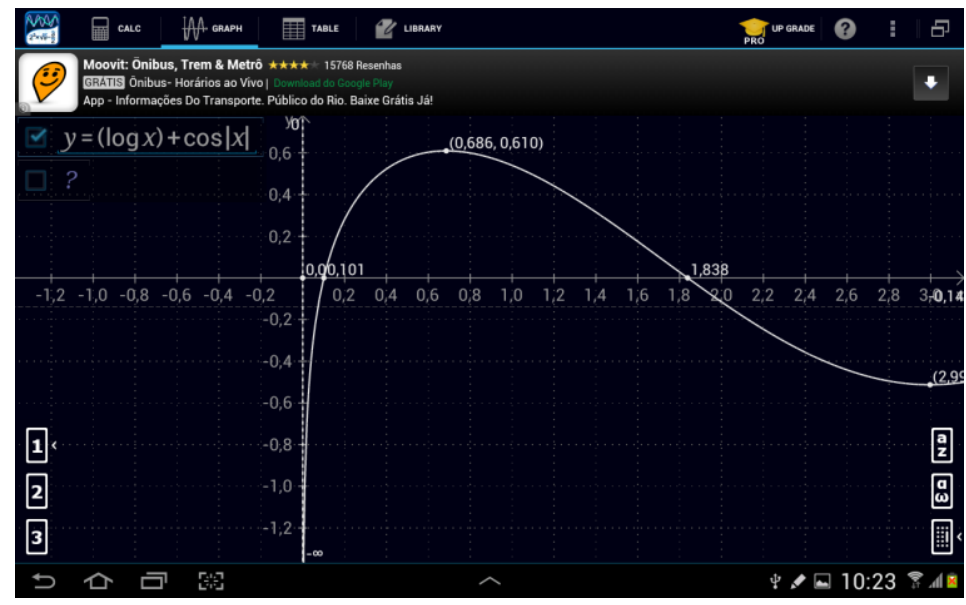

Figura 27-Zoom no gráfico gerado.

(Fonte: Elaboração dos autores.)

Além do recurso de se trabalhar com a construção de gráficos, o programa possibilita o trabalho com expressões numéricas, trigonométricas, porcentagens, matrizes, números complexos, resultado do valor numérico de uma expressão algébrica, determinação das raízes de equações polinomiais, matrizes, vetores e tabelas como parte da construção de gráficos.

\subsection{Resultados}

Na tabela seguinte ilustramos como catalogamos cada aplicativo, anteriormente descritos. 
Tabela 1 - Síntese dos Aplicativos capturados.

\begin{tabular}{|c|c|c|c|c|}
\hline Desenvolvedores & $\begin{array}{l}\text { Aplicativos } \\
\text { (App) }\end{array}$ & Temática & Sujeitos & Data de acesso \\
\hline $\begin{array}{l}\text { Toennies et al. } \\
\text { (2011) }\end{array}$ & $\begin{array}{l}\text { Tablet } \\
\text { (Android) }\end{array}$ & $\begin{array}{l}\text { Elementos do } \\
\text { plano } \\
\text { Cartesiano: } \\
\text { malhas, pontos, } \\
\text { linhas e formas }\end{array}$ & $\begin{array}{l}\text { Estudantes com } \\
\text { deficiência visual }\end{array}$ & $\begin{array}{l}07 / 04 / 2013 \\
17 / 04 / 2013\end{array}$ \\
\hline $\begin{array}{l}\text { Barendregt et } \\
\text { al. (2012) }\end{array}$ & Fingu (jogo) & Contagem & $\begin{array}{l}\text { Crianças } \\
\text { pequenas }\end{array}$ & $17 / 04 / 2013$ \\
\hline lijima (2012) & $\begin{array}{l}\text { Geometric } \\
\text { Constructer } \\
\text { (GC) }\end{array}$ & $\begin{array}{l}\text { Geometria } \\
\text { (plana) }\end{array}$ & $\begin{array}{l}\text { Estudantes do } \\
\text { Ensino Médio }\end{array}$ & 06/04/2013 \\
\hline $\begin{array}{l}\text { Ladel e } \\
\text { Kortenkamp } \\
\text { (2012) }\end{array}$ & $\begin{array}{l}\text { Numeration } \\
\text { Tabuleiro Multi- } \\
\text { touch (MTT) }\end{array}$ & $\begin{array}{l}\text { Números no } \\
\text { sistema decimal } \\
\text { e operações } \\
\text { básicas }\end{array}$ & $\begin{array}{l}\text { Crianças } \\
\text { pequenas }\end{array}$ & $18 / 04 / 2013$ \\
\hline $\begin{array}{l}\text { Pelton e } \\
\text { Pelton (2012) }\end{array}$ & $\begin{array}{l}\text { MathTappers } \\
\text { (APP) }\end{array}$ & $\begin{array}{l}\text { Representação } \\
\text { na reta Real } \\
\text { Operações } \\
\text { básicas } \\
\text { Porcentagens } \\
\text { (representações } \\
\text { gráficas) }\end{array}$ & $\begin{array}{l}\text { Crianças } \\
\text { pequenas }\end{array}$ & 06/04/2013 \\
\hline $\begin{array}{l}\text { Wassermann, } \\
\text { Alfred (2012) }\end{array}$ & Sketchometry & $\begin{array}{l}\text { Geometria } \\
\text { (plana) }\end{array}$ & $\begin{array}{l}\text { Estudantes do } \\
\text { Ensino } \\
\text { Fundamental e } \\
\text { Médio }\end{array}$ & $18 / 05 / 2013$ \\
\hline $\begin{array}{l}\text { Nicholas } \\
\text { Jackiw (2012) }\end{array}$ & $\begin{array}{l}\text { Geometer'sSket } \\
\text { chpad no iPad }\end{array}$ & $\begin{array}{l}\text { Transformações, } \\
\text { medida e } \\
\text { estimação }\end{array}$ & $\begin{array}{l}\text { Estudantes do } \\
\text { Ensino } \\
\text { Fundamental e } \\
\text { Médio }\end{array}$ & $\begin{array}{l}05 / 04 / 2013 \\
19 / 04 / 2013\end{array}$ \\
\hline $\begin{array}{l}\text { MarkusHohen } \\
\text { Warter (2013) }\end{array}$ & $\begin{array}{l}\text { GeoGebra } \\
\text { tabletsapps }\end{array}$ & $\begin{array}{l}\text { Geometria, } \\
\text { álgebra e cálculo }\end{array}$ & $\begin{array}{l}\text { Ensino } \\
\text { fundamental a } \\
\text { graduação }\end{array}$ & $20 / 10 / 2013$ \\
\hline
\end{tabular}


Bytes

Arithmetic LLC Geometry Pad

(2013)

José

Alexandre

Macedo

(2013)

Mathlab.us

LLC (2012)
Multibase

Sistema de numeração de base

Álgebra,
Geometria
analítica e
Funções
Caculator by

Mathlab
Ensino

Geometria plana

fundamental a

graduação

$19 / 09 / 2013$

Séries iniciais do

ensino

$13 / 11 / 2013$

fundamental

Ensino

fundamental a

graduação
$13 / 11 / 2013$

(Fonte: Elaboração dos autores.)

Adotamos as nomenclaturas softwares e jogos, para classificar os aplicativos descritos anteriormente. Pois, a partir das descrições foi possível perceber que alguns dispositivos têm a característica de realizar tarefas complexas e de cunho livre, isto é, o usuário decide o que deseja criar, possuem interfaces funcionais e simples em sua maioria com uma tela inicial em branco o que se assemelha ao padrão dos softwares como Winplot e o Geogebra, por exemplo. Enquanto que outros aplicativos apresentam atividades pontuais com regras pré-definidas, interfaces com design colorido assemelhando-se aos jogos. (TABELAS 2 e 3)

Os jogos oferecidos pelos aplicativos servem também como um instrumento de reforço ao que é dado pelo professor em sala de aula, pois no momento em que o aluno brinca com um determinado jogo ele intensifica sua aprendizagem. Na tabela 2 apresentamos os aplicativos que classificamos como jogos.

Tabela 2 - Aplicativos classificados como jogos

Aplicativos

MathTapper - numberline

MathTapper - findsums

MathTapper - Multiples

MathTapper - Clockmaster

MathTapper - Estimate Fractions

\section{Temática}

Números reais e representação na reta real

Operações: soma e subtração

Multiplicação e divisão de números inteiros

Leitura do tempo em relógio digital e analógico

Estimativa de frações e operações com frações 
MathTapper - Equivalentes

Fingu

Numeration
Frações equivalentes, representação

decimal e porcentagem

Contagem

Números no sistema decimal e operações básicas

Fonte: Elaboração dos autores.

Através dos levantamentos feitos observamos a existência de dois tipos de softwares. Os que estão em fase de teste e reajustes como o Hapticand Aural Exploration Software (software para deficientes visuais), Geogebra Tablets Apps e o Sketchometry, em particular, o Haptic and Aural Exploration Software apresenta somente atividades de caráter geral e ilustrativas. E softwares como Geometer's Sketchpad e o Geometric Constructer, que proporcionam ambientes estruturados e prontos para o uso, o Geometer's Sketchapad, por exemplo, oferece tutorias e sugestões de atividades para que o professor possa se inspirar e se guiar na elaboração de suas próprias ideias. Nesse tipo que estamos mais interessados, principalmente, por estarem mais próximos do nosso interesse temático: a geometria.

Tabela 3 - Aplicativos classificados como softwares

Estado em que

Softwares

Temática

Público alvo

Alunos do

Haptic and Aural Geometria plana e

Exploration Software álgebra

$\begin{array}{ll}\text { Sketchometry } & \text { Geometria plana } \\ & \\ \text { Geometric } & \text { Construções de } \\ \text { Constructer } & \text { geometria plana } \\ & \\ & \\ \text { Geometer's } & \text { Transformações, } \\ \text { Sketchpad } & \text { medida e estimação }\end{array}$

Alunos do

Ensino

Fundamental e Versão beta do Ensino

Médio

Alunos do

Ensino

Fundamental e

do Ensino

Médio

Alunos do

Ensino

Fundamental e Pronto para o

do Ensino

uso
Pronto para o

uso

software

Fase de testes

Médio

DOI: Em andamento. 


$\begin{array}{llll}\begin{array}{l}\text { Geogebra tablets } \\ \text { apps }\end{array} & \begin{array}{l}\text { Geometria, álgebra } \\ \text { e cálculo }\end{array} & \begin{array}{l}\text { Ensino } \\ \text { fundamental a } \\ \text { graduação }\end{array} & \text { Versão beta } \\ \text { Geometry Pad } & \text { Geometria Plana } & \begin{array}{l}\text { Ensino } \\ \text { fundamental a } \\ \text { graduação }\end{array} & \begin{array}{l}\text { Pronto para o } \\ \text { uso }\end{array} \\ \text { Multibase } & \begin{array}{l}\text { Sistema de } \\ \text { numeração e valor } \\ \text { posicional }\end{array} & \begin{array}{l}\text { ensino } \\ \text { fundamental }\end{array} & \text { Pronto para o } \\ & \begin{array}{l}\text { Álgebra, Geometria } \\ \text { analítica e Funções }\end{array} & \begin{array}{l}\text { Ensino } \\ \text { fundamental a } \\ \text { graduação }\end{array} & \text { Pronto para o } \\ \text { Graphing Caculator } \\ \text { by Mathlab }\end{array}$

Fonte: Elaboração dos autores.

A partir da tabela 3 destacamos que a temática predominante nos softwares é a geometria. Já nos aplicativos classificados como jogos (TABELA 2) o tema que mais aparece é a álgebra. Portanto, esses recursos além de auxiliarem na aprendizagem permitem a exploração de uma variedade de conteúdos matemáticos.

Finalmente, apesar de nossa pesquisa estar orientada para o uso de aplicativos e softwares no ensino da matemática em dispositivos móveis e ubíquos um equipamento muito interessante que nos chamou a atenção e que pensamos ser importante divulgar é o Phantom Omni.

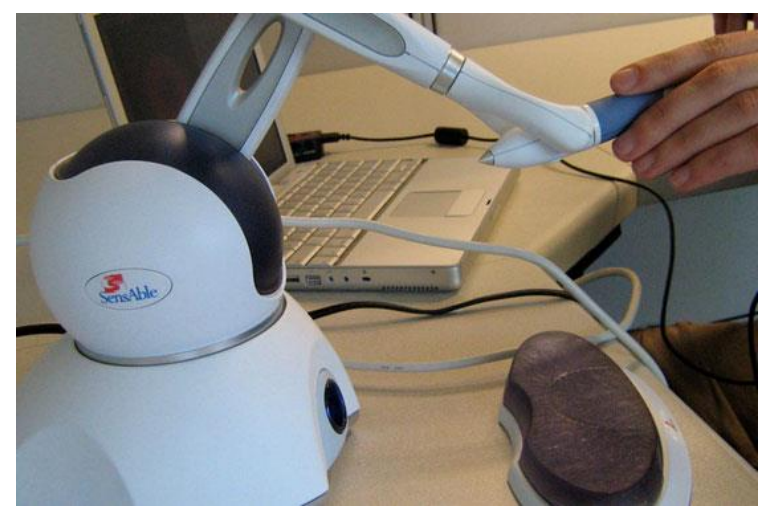

Figura 28 - PhantomOmni

(Fonte: Keycurriculum (2013))

O Phantom Omni é um dispositivo visual e tátil fornecido pela empresa Geomagic. Que proporciona ao usuário esculpir e manipular objetos em 3D. É um dispositivo motorizado que aplica uma reação de força na mão do usuário, permitindo-Ihe sentir objetos virtuais e produz sensações 
de toque quando o mesmo os manipulam na tela. Ele está em desenvolvimento na universidade de Massachusetts.

A partir da catalogação ora realizada, no momento atual de nossa pesquisa selecionamos os softwares Sketchometry e o Geometric Constructer para elaborar e implementar atividades com estudantes. A seguir na próxima seção apresentaremos esses resultados.

\section{Implementando atividades nos softwares GC e Sketchometry}

Visando estudar melhor na prática como funcionam estes softwares selecionamos algumas atividades relacionadas a geometria euclidiana e aplicamo-nas em um grupo de três alunos, todos graduandos em licenciatura matemática. Foram realizadas até o momento apenas duas seções dessas implementações e cada seção utilizamos um dos softwares. No primeiro encontro ocorrido em julho utilizamos o software Skecthometry, mas obtivemos um rendimento baixo com relação a quantidade de atividades que conseguimos trabalhar, entretanto a qualidade da atividade e as respostas dos alunos foram bastante satisfatória. No segundo encontro que ocorreu em agosto trabalhamos com o software GC conseguimos aplicar três atividades, entretando conseguimos concluir duas.

Cada aluno recebeu um tablete e as atividades foram expostas em slides. Por fim os alunos receberam um folha em branco para que os mesmos discorressem brevemente a respeito de suas própias impreções dos softwares trabalhados.

A tabela 4 ilustra uma síntese das atividades desenvolvidas no GC.

Tabela 4 - Atividades implementadas no GC
Atividade
Objetivo

Conhecendo o Software

Teorema de Thébault

Teorema de Varignon

Fonte: Elaboração dos autores.
Obter domínio e se familiarizar com o software.

Traçar estratégias para construir o problema e conjecturar acerca do mesmo.

Conjecturar e chegar ao resultado que o teorema apresenta.

DOI: Em andamento. 
A seguir ilustramos detalhadamente cada atividade.

Atividade 1: Conhecendo o Software - Explorando as ferramentas do GC, desenhe a figura a seguir.

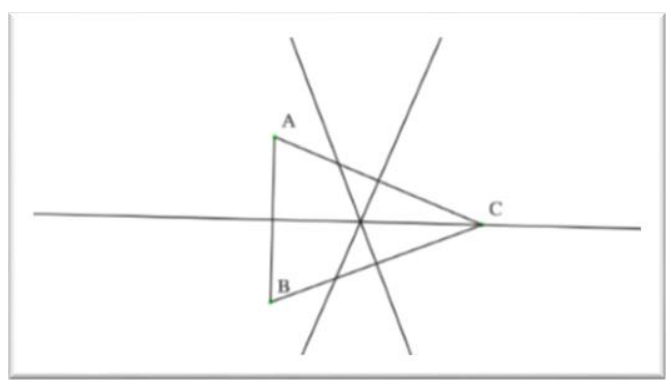

Neste primeiro momento nosso objetivo era que os colaboradores apenas se familiarizassem com o GC, para que futuramente conseguíssemos aplicar as demais atividades. A princípio os alunos demoraram um pouco a tomar segurança para manipular o GC. Alguns preferiram realizar pequenas construções a fim de conhecer cada vez mais o software. Mas assim que os mesmos adquiriram confiança, finalizaram a tarefa.

As questões a seguir foram implementadas com o intuito de questionar os discentes sobre o uso do software para abordar determinado conteúdo matemático.

Atividade 2: Teorema de Thébault - Construa um quadrilátero qualquer. E em cada lado do quadrilátero construa um quadrado. Trace as diagonais de cada quadrado. A partir das diagonais obtém-se os centros de cada quadrado. Ligue os centros opostos e construa um novo quadrilátero a partir desses pontos. Que quadrilátero é esse?

Tabela 5- Atividade: Teorema de Thébault.

\section{Alguns momentos da atividade Legenda das imagens}

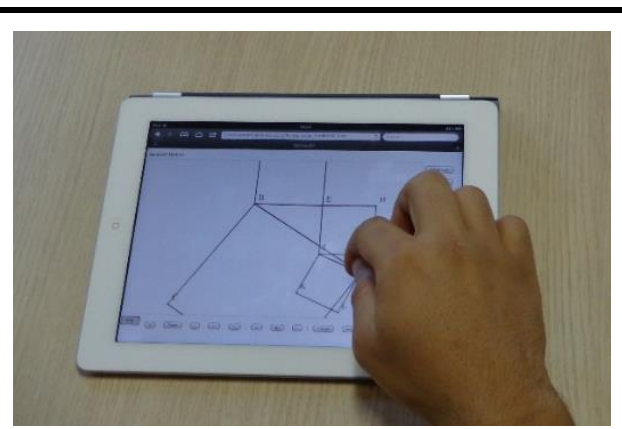

Aluno F: movimenta a construção para verificar se a mesma está de acordo com os requisitos solicitados na atividade. 


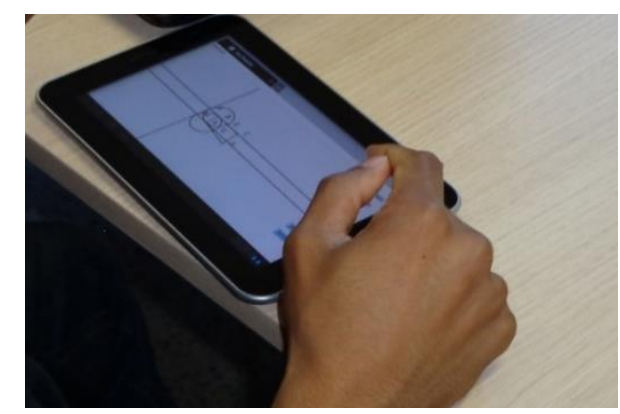

Aluno V: traça estratégias de construção geométrica para realizar a atividade.

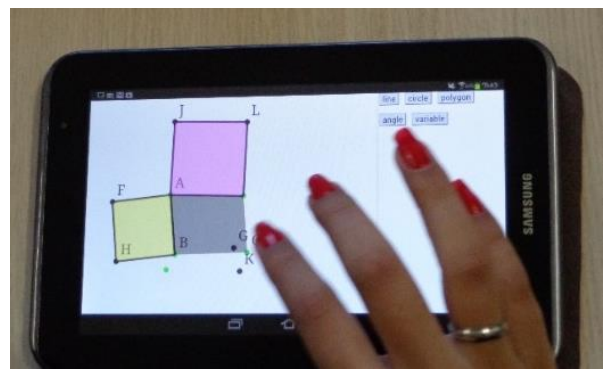

Aluno T: Edita a construção para dar continuidade a atividade.

(Fonte: Elaboração dos autores.)

Neste exercício cada aluno traçou uma estratégia diferente para realizar as construções. Logo em seguida alguns dos graduandos começaram a trocar suas ideias. Em quanto outro ainda tentava traçar uma melhor resolução para a problemática. Entretanto, devido à extensão da atividade ocorreram muita lentidão e travamentos no GC.

Atividade 3: Teorema de Varignon - Construa um quadrilátero $A B C D$ qualquer, e em cada lado de $A B C D$ obtenha os pontos médios. Em seguida ligue os pontos médios $E, F, G, H$ de modo que se obtenha um novo quadrilátero. O que você pode afirmar sobre a característica de EFGH? Demonstre.

Tabela 6 - Atividade: Teorema de Varignon.

\section{Alguns momentos da atividade Legenda das imagens}

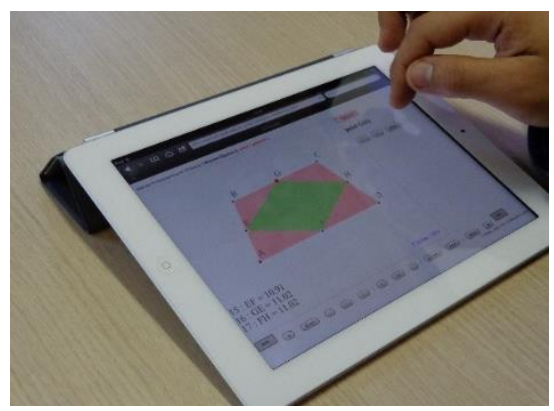

Aluno F: Utiliza as ferramentas de medição para verificar as propriedades do quadrilátero verde da imagem ao lado.

DOI: Em andamento. 


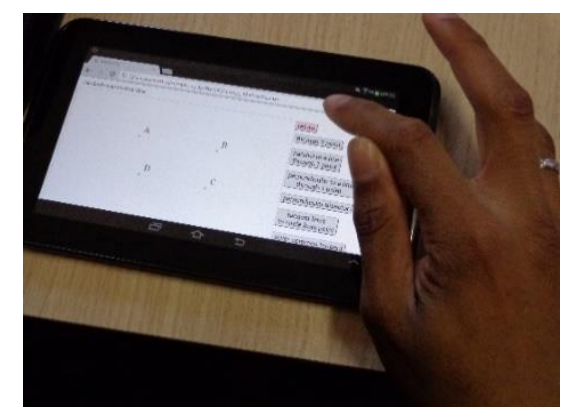

Aluno V: Realiza os primeiros

passos para a construção de um quadrilátero qualquer.

(Início da atividade)

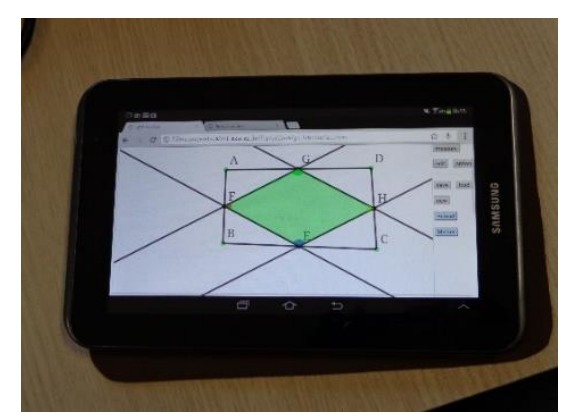

Construção realizada pelo

aluno T. (construção pronta)

(Fonte: Elaboração dos autores.)

Esta última atividade foi a que obteve melhor resultado no âmbito da aprendizagem, pois todos os alunos conseguiram terminar suas construções com êxito e realizaram conjecturas acerca da problemática em questão. Logo sugerimos que os mesmos tentassem demonstrar a seguinte proposição: "Se $A B C D$ é um quadrado então o quadrilátero construído a partir de seus pontos médios também é um quadrado". Ainda não foi possível questionar e instigar os alunos a chegarem à definição do teorema de Varignon. Contudo, consideramos validos os debates e questionamentos feitos durante o piloto, pois estes levam os alunos a uma posição de autonomia e investigação o que contribui para a construção do conhecimento dos mesmos, além de enriquecer nossa pesquisa.

Apresentaremos agora as atividades desenvolvidas no Sketchometry.

Tabela 7 - Atividades desenvolvidas no Sketchometry

Atividade

Conhecendo o software

Bissectograma

\section{Objetivo}

Obter domínio e se familiarizar com o software.

Construir o problema e conjecturar sobre o mesmo.

(Fonte: Elaboração dos autores.) 
Detalhamento das atividades da tabela 5.

Atividade 1: Conhecendo o software - Este exercício foi totalmente livre, os alunos manipularam o software da forma que almejaram.

Neste momento os alunos estavam entusiasmados e não foi necessário solicitar que os mesmos manipulassem o Skecthometry, pois eles por si só começaram a realizar pequenas construções e rapidamente se familiarizaram com o software.

Atividade 2: Bissectograma - O bissectograma é o quadrilátero que se obtém por interseção das bissetrizes dos quatro ângulos de um quadrilátero. Utilizando as ferramentas do software desenhe um quadrilátero qualquer e trace as bissetrizes de seus quatro ângulos internos. Sempre existe um bissectograma? Para determinados quadriláteros o bissectograma é um quadrilátero particular. Que relação existe entre o quadrilátero inicial e o bissectograma? Por que isso acontece? O que acontece se for um trapézio isósceles?

Tabela 8-Atividade: Bissectograma

\section{Alguns momentos da atividade Legenda das imagens}

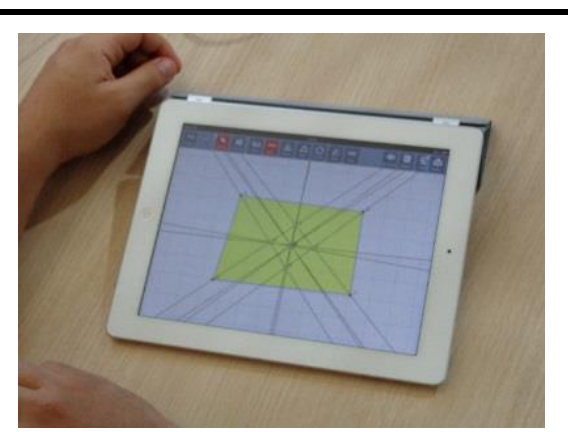

Construção do bissectograma pronta realizada pelo aluno $\mathrm{F}$. No caso em que se tem um quadrilátero qualquer.

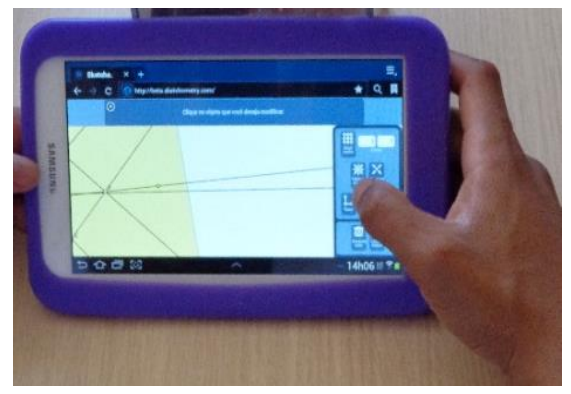

Aluno $\mathrm{V}$ ampliando a construção para verificar se formou um bissectograma.

(Fonte: Elaboração dos autores.)

DOI: Em andamento. 
Nesta segunda atividade, logo de início os alunos sentiram dificuldade para traçar a bissetriz de cada ângulo do quadrilátero, pois exigia um controle maior da coordenação motora. No entanto, todos conseguiram finalizar a atividade, todos interagiram, trocaram ideias e conjecturaram acerca do problema. Dois alunos construíram um trapézio isósceles de forma distinta e ninguém o construiu de maneira formal por construção geométrica. A tabela a seguir ilustra as ideias que cada aluno teve para construir o trapézio isósceles. (TABELA 6)

Tabela 9-Estratégias dos alunos
Aluno F
Aluno V/ AlunoT
Construiu o trapézio isósceles
Utilizou a malha quadriculada. Logo
utilizando três quadrados iguais um após mediu e verificou as ao lado do outro. propriedades do trapézio isósceles.
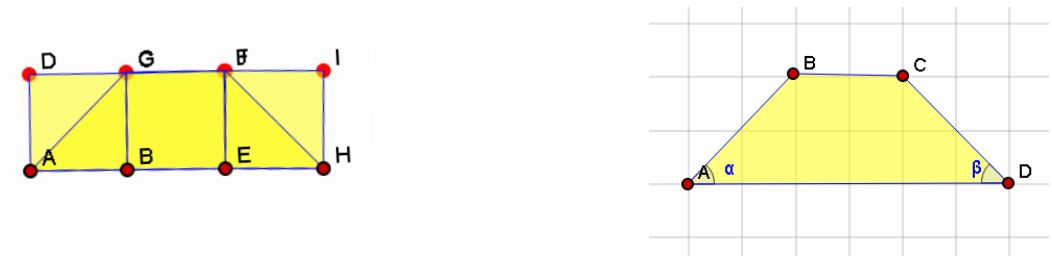

(Fonte: Elaboração dos autores.)

\subsection{Reflexões dos graduandos sobre o trabalho nos Softwares}

Neste momento apresentamos uma prévia das análises que estão sendo realizadas sobre os softwares selecionados. No trabalho exploratório realizado nos softwares os aspectos que mais se destacaram foram:

- Quantidade de ferramentas que cada software possui;

- Zoom;

- Tempo para realizar as construções.

A tabela a seguir sintetiza os depoimentos de cada aluno com relação ao $\mathrm{GC}$ e o Sketchometry. 
Tabela 10 - Depoimento dos graduandos sobre o GC.

Aluno F

Aluno V

Aluno T

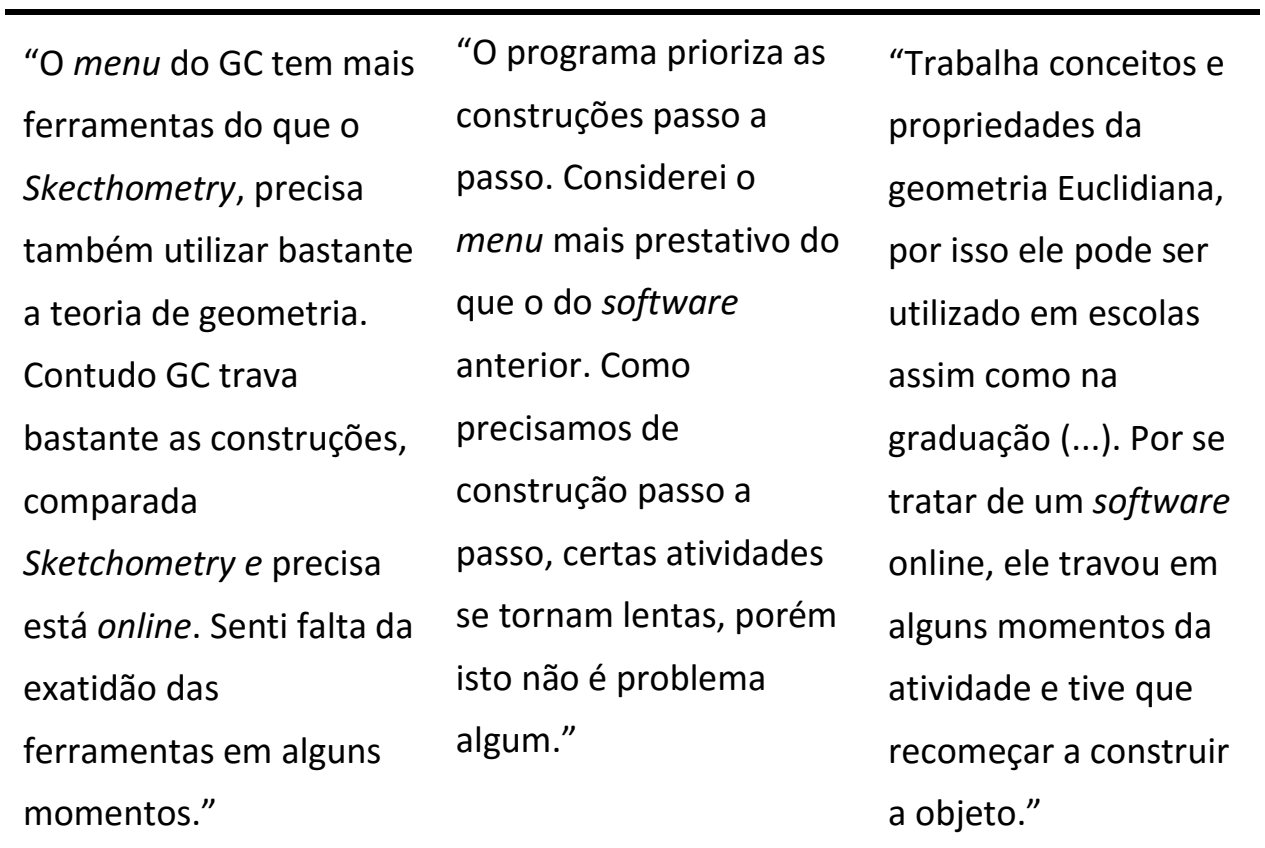

(Fonte: Elaboração dos autores.)

Tabela 11 - Depoimentos dos graduandos sobre o Sketchometry Aluno $\mathrm{F}$

Aluno V

Atuno T

\begin{tabular}{lll}
\hline “(...) temos que utilizar & “Programa de construção & "O software é mais \\
bastante da teoria de & rápida, porém considerei & livre, as funções são \\
geometria para fazer as & o menu muito vazio, ou & simples, mas este não \\
construções geométricas & seja, com poucas & é baseado nas \\
nele, porém precisa estar & ferramentas. Me senti & propriedades de \\
conectado na internet & dependente dos & geometria Euclidiana. \\
que às vezes pode dar & apresentadores." & Ponto negativo: \\
problema na conexão & & dependência de \\
logo software para de & & conexão com a \\
funcionar. Também senti & & internet prejudica a \\
falta na exatidão das & & oficina." \\
ferramentas." & &
\end{tabular}

(Fonte: Elaboração dos autores.) 
A princípio consideramos o GC um software adequado para construções rápidas. É um recurso de fácil entendimento devido a sua variedade de ferramentas. Além, de exigir muito do conhecimento do aluno com relação à geometria.

As limitações que mais se destacaram no GC foram:

- A lentidão em algumas construções devido ao fato de ter que selecionar uma ferramenta de cada vez o que pode ocasionar a necessidade de um tempo maior na execução da atividade;

- A ferramenta zoom, a ampliação vai apenas até um determinado tamanho, o que nos faz repensar nas atividades propostas;

- Travamentos devido à instabilidade na conexão com a internet.

No que concerne ao Sketchometry, observamos a pouca presença de ferramentas em sua interface, entretanto estas funções podem ser recompensadas através dos movimentos na tela do dispositivo. Isto é, se o indivíduo quiser construir uma circunferência, por exemplo, não existe a ferramenta círculo ou circunferência basta o mesmo tocar na tela e desenhar um círculo com a ponta dos dedos. Consideramos este modo de realizar a construção é eficaz, pois deixa a execução das atividades mais rápida.

Limitações que mais se destacaram foram:

- Zoom limitado;

- Travamentos devido à instabilidade na conexão com a internet.

Portanto, os softwares possuem praticamente os mesmos problemas, contudo avaliamos que ambos podem contribuir para o ensino e aprendizagem do aluno, pois possuem um ambiente livre que permite seus usuários explorarem e investigarem diversas situações da geometria que com o papel levariam muito tempo. Além de contribuir para a visualização dos alunos, já que não é uma construção estática, os mesmos podem descrever e perceber as propriedades de um determinado objeto ou situação com mais facilidade.

\section{Considerações finais}

O levanto ora apresentado e analisado, de um modo geral, ilustra a variedade de recursos informáticos que estão sendo elaborados para o ensino da Matemática. Esperamos, assim, que a leitura desse artigo instigue o leitor para o uso da tecnologia digital móvel como mais uma alternativa didática em sua prática e como mais uma possibilidade de ampliação dos espaços de aprendizagem. Relacionados à nossa questão de pesquisa, particularmente, nosso estudo traz contribuições sobre a natureza dos aplicativos touchscreen, desenvolvidos ou em desenvolvimento. 
Embora todos os dispositivos mapeados sejam softwares, ou seja, programas informáticos, optamos por classificá-los considerando em os aplicativos (APPS) ou softwares propriamente. Para essa classificação consideramos três naturezas: técnicas (do âmbito da informática), do propósito da tarefa e da possibilidade de deflagrar a interação.

Tabela 12 - Critérios de classificação para APPs e softwares

\begin{tabular}{|c|c|c|}
\hline Natureza & Software & APPs \\
\hline Técnica (de processo) & $\begin{array}{l}\text {-Robustez } \\
\text {-Processamento mais } \\
\text {-Arquivos podem ser } \\
\text { salvos }\end{array}$ & $\begin{array}{l}\text {-Soft } \\
\text {-Processamento de } \\
\text { dados é mais rápido } \\
\text {-Manuseios não } \\
\text { podem ser salvos }\end{array}$ \\
\hline Design & $\begin{array}{l}\text { Geralmente é mais } \\
\text { simples em sua aparência } \\
\text { e apresenta uma tela } \\
\text { inicial em branco com } \\
\text { barras de tarefas }\end{array}$ & $\begin{array}{l}\text { É mais atrativo, } \\
\text { aspecto colorido }\end{array}$ \\
\hline Tarefa & $\begin{array}{l}\text { Possibilita a construção de } \\
\text { objetos não pré- } \\
\text { determinados }\end{array}$ & $\begin{array}{l}\text { Situações mais } \\
\text { fechadas, algumas } \\
\text { em caráter tutorial } \\
\text { ou de jogo }\end{array}$ \\
\hline Interação & $\begin{array}{l}\text { Pode ter um caráter e } \\
\text { manuseio mais coletivo } \\
\text { ou investigativo }\end{array}$ & $\begin{array}{l}\text { Tende a ser mais } \\
\text { individualizada e com } \\
\text { possibilidade de } \\
\text { descoberta orientada } \\
\text { pelo próprio } \\
\text { aplicativo }\end{array}$ \\
\hline
\end{tabular}

(Fonte: Elaboração dos autores.)

Os aplicativos são em sua maioria jogos e trabalham com temas relacionados à aritmética. Os softwares constituem ambientes mais livres e dinâmicos e sua abordagem está mais voltada para tópicos geométricos. Como o tema dos dispositivos touchscreen alguns recursos ainda estão em desenvolvimento e em fase de testes.

O levantamento feito sobre os aplicativos e softwares destinados ao ensino da Matemática possibilitou a observação de problemas que poderiam gerar limitações na utilização dessas tecnologias em sala de aula, como o idioma ou o sistema operacional, por exemplo. No que tange

DOI: Em andamento. 
ao idioma esse tipo de estudo pode instigar uma maior produção portuguesa para esse tipo de recurso.

Consideramos no âmbito curricular que o ambiente criado com as atividades aplicadas junto aos softwares através dos tablets propicia a aprendizagem, pois estimula a exploração e investigação por parte dos discentes, visto que não foram apresentados os resultados dos teoremas utilizados nas atividades, os alunos foram quem descobriram estes resultados a partir das instruções que lhes foram dadas, assim os mesmos foram levados cognitivamente a pensar matematicamente relembrando e descobrindo novas propriedades geométricas. Sendo assim, acreditamos que nossa pesquisa possa contribuir para a reflexão dos leitores acerca dos ambientes de aprendizagem que docentes devem proporcionar ao seu alunado visando à autonomia na construção do conhecimento.

Com relação às atividades implementadas nos softwares selecionados, consideramos que estas serviram para aprimorar nosso trabalho. Visto que a partir das implementações tivemos a oportunidade de perceber os avanços que podemos obter em sala de aula com a utilização dos softwares, como os alunos reagem e se iteram da tecnologia digital e como se desenvolve o raciocínio e a aprendizagem através da mediação dos softwares. Outro ponto importante são as limitações dos softwares que nos levam a refletir sobre novas estratégias ou atividades a serem implementadas que contornem os problemas inesperados.

\section{Referências}

AMARAL, P. G. R. Softwares Matemáticos e Estatísticos pata tablets: Uma primeira análise. 2013. 64 f. Dissertação - PROFMAT, Universidade Federal Fluminense, Niterói. 2013

BAIRRAL, M. A. Do clique ao touchscreen: Novas formas de interação e de aprendizado matemático. Anais ... 36 Reunião da Anped. Goiânia, 2013. Disponível em http://36reuniao.anped.org.br/pdfs_trabalhos_aprovados/gt19_trabalhos_pdfs/gt19_2867_texto .pdf

BAIRRAL, M. Moving from dragging to touchscreen: new challenges on learning with GDS Relatório de pesquisa: EstágioSênior. Universidade de Turin. Processo Capes - BEX 8845-11/5. $20 \mathrm{p}$.

BASHERI, M., BURD, L., MUNRO, M., \& BAGHAEI, N. Enhancing Engagement and Collaborative Learning Skills in Multiltouch Software for UML Diagramming. Anais ... CSCL 2013. Madison: USA. BYTES ARITHMETIC L.L.C. Geometry Pad, 2013. Disponível em: <http://www.stemonmobile.com/>. Acesso: 19 set. 2013.

DOYUN, P. A Study on the Affective Quality of Interactivity by Motion Feedback in Touchscreen User Interfaces. Tese. KAIST (Korea): Graduate School of Culture Technology, 2011.

72 DOI: Em andamento. R. Bras. de Ensino de C\&T 
GEOGEBRA, Geobebra tablets apps, 2013.

Disponível em:<http://blog.geogebra.org/2013/09/geogebra-tablet-apps/> Acesso em: 20 out. 2013.

IIJIMA, Y., Geometric Constructer, 2012. Disponível em: <http://yiijima.sakura.ne.jp/ wiki/ e01/index.php?How\%20to\%20make\%20and\%20save\%20a\%20new\%20figure>. Acesso em: 06 abr. 2013.

ITUNES. Geometer's Sketchpad, 2012. Disponível em: <https://itunes.apple.com/us/app/ sketchpad-explorer/id452811793?ls=1\&mt=8>. Acesso em: 05 abr. 2013.

ITUNES, Math Tapper_numberline, Description, 2012. Disponivel em: < https://itunes. apple.com/us/app/mathtappers-numberline-math/id463632109?mt=8>. Acesso em: 06 abr. 2013.

ITUNES, Math Tapper_find sums, Description, 2012. Disponível em: $<$ https://itunes. apple. com/us/app/id353582286?mt=8>. Acesso em: 06 abr. 2013.

ITUNES, Math Tapper_Multiples, Description, 2012. Disponívelem: < https://itunes.apple. com/us/app/id353582286?mt=8>. Acessoem: 06 abr. 2013.

ITUNES, Math Tapper_Clockmaster, Description, 2012. Disponível em: <https://itunes. apple. com/us/app/id353582286?mt=8>.Acesso em: 06 abr. 2013.

ITUNES, Math Tapper_Estimate Fractions, Description, 2012. Disponível em: <https://itunes.apple.com/us/app/id353582286?mt=8>. Acesso em: 06 abr. 2013.

ITUNES, Math Tapper_Equivalentes, Description, 2012. Disponível em: $<$ https://itunes. apple.com/us/app/id353582286?mt=8>. Acesso em: 06 abr. 2013.

ITUNES, Fingu, 2012. Disponível em: < https://itunes.apple.com/br/app/fingu/ id449815506?mt=8>. Acesso em: 17 abr. 2013.

ITUNES, Numeration, 2012. Disponível em: <https://itunes.apple.com/pt/app/numeracao/ id568750442? mt=8>. Acesso em: 18 abr. 2013.

JACKIW, Nicholas. Geometer's Sketchpad, 2012. Disponível em: <http://www.key curriculum.com/resources/sketchpad-resources/sketchpad-explorer-for-ipad>. Acesso em: 05 abr. 2013.

KAPUTCENTE, 2012. Disponível em:<http://www.kaputcenter.umassd. edu/projects /haptic/OmniActivities/>. Acesso em: 18 maio 2013.

KEYCURRICULUM. Disponível em:<http://www.keycurriculum.com/about/research-partners>. Acesso em: 18 maio 2013.

DOI: Em andamento. 
MACEDO, J. A. Multibase, 2012. Disponível em:<

https://play.google.com/store/apps/details?id=com.multibase\&hl=pt_BR>Acesso: 13 nov. 2013.

MATHLAB.US LLC. Graphing Caculator by Mathlab, 2013 . Disponível em:< http://www.mathlab.us/calc/index.html> Acesso: 19 set. 2013

PELTON, Tim, Math Tappers,2012. Disponível em:<http://www.mathtappers.com/>. Acesso em:

06 abr. 2013.

SALISBURY, David, Haptic and Aural Exploration Software, 2012. Disponível em:

<http://news.vanderbilt.edu/2012/03/haptic-tablet/>. Acesso em: 07 abr. 2013.

SANTOS, E. Cibercultura, Educação On-line e Processos Culturais. Teias, 13 (30), p. 3-8, 2012.

TANG, A. et al. VisTACO: Visualizing Tabletop Collaboration. International Conference on Interactive Tabletops and Surfaces (ITS '10). Anais ... International Conference on Interactive Tabletops and Surfaces (ITS '10). Saarbrücken, Alemanha, 2010.

WASSERMANN, Alfred, Sketchometry, 6 jul. 2012. Disponível em:

< http://www. sketchometry .com/>. Acesso em: 18 maio 2013.

' Por exemplo, o trabalho de Amaral (2013) apresenta um levantamento no qual o clique ainda é o tipo de ação priorizada no dispositivo.

Marcelo Almeida Bairral - Professor, Universidade Federal Rural do Rio de Janeiro (PPGEduc e PPGEduCIMAT).E-mail:mbairral@ufrri.br

Alexandre Rodrigues de Assis - Mestrando, Universidade Federal Rural do Rio de Janeiro (PPGEduc). E-mail: profalexandreassis@hotmail.com

Bárbara Caroline C.C. da Silva - Mestranda, Universidade Federal Rural do Rio de Janeiro (PPGEduCIMAT). E-mail: barbaracarolinecardoso@hotmail 